\title{
Surveillance for Violent Deaths - National Violent Death Reporting System, 17 States, 2013
}




\section{CONTENTS}

Introduction

The MMWR series of publications is published by the Center for Surveillance, Epidemiology, and Laboratory Services, Centers for Disease Control and Prevention (CDC), U.S. Department of Health and Human Services, Atlanta, GA 30329-4027.

Suggested citation: [Author names; first three, then et al., if more than six.] [Title]. MMWR Surveill Summ 2016;65(No. SS-\#):[inclusive page numbers].

\section{Centers for Disease Control and Prevention}

Thomas R. Frieden, MD, MPH, Director

Harold W. Jaffe, MD, MA, Associate Director for Science

Joanne Cono, MD, ScM, Director, Office of Science Quality

Chesley L. Richards, MD, MPH, Deputy Director for Public Health Scientific Services

Michael F. Iademarco, MD, MPH, Director, Center for Surveillance, Epidemiology, and Laboratory Services

\section{MMWR Editorial and Production Staff (Serials)}

Sonja A. Rasmussen, MD, MS, Editor-in-Chief

Charlotte K. Kent, $\mathrm{PhD}$, MPH, Executive Editor Christine G. Casey, MD, Editor

Teresa F. Rutledge, Managing Editor

David C. Johnson, Lead Technical Writer-Editor

Marella Meadows, Project Editor
Martha F. Boyd, Lead Visual Information Specialist

Maureen A. Leahy, Julia C. Martinroe,

Stephen R. Spriggs, Moua Yang, Tong Yang, Visual Information Specialists

Quang M. Doan, MBA, Phyllis H. King, Terraye M. Starr, Information Technology Specialists
MMWR Editorial Board

Timothy F. Jones, MD, Chairman Matthew L. Boulton, MD, MPH Virginia A. Caine, MD

Katherine Lyon Daniel, $\mathrm{PhD}$

Jonathan E. Fielding, MD, MPH, MBA

David W. Fleming, MD
William E. Halperin, MD, DrPH, MPH

King K. Holmes, MD, PhD

Robin Ikeda, MD, MPH

Rima F. Khabbaz, MD

Phyllis Meadows, PhD, MSN, RN

Jewel Mullen, MD, MPH, MPA
Jeff Niederdeppe, PhD

Patricia Quinlisk, MD, MPH

Patrick L. Remington, MD, MPH Carlos Roig, MS, MA

William L. Roper, MD, MPH

William Schaffner, MD 


\title{
Surveillance for Violent Deaths - National Violent Death Reporting System, 17 States, 2013
}

\author{
Bridget H. Lyons, $\mathrm{MPH}^{1}$ \\ Katherine A. Fowler, $\mathrm{PhD}^{1}$ \\ Shane P.D. Jack, $\mathrm{PhD}^{1}$ \\ Carter J. Betz, MS ${ }^{1}$ \\ Janet M. Blair, $\mathrm{PhD}^{1}$ \\ ${ }^{1}$ Division of Violence Prevention, National Center for Injury Prevention and Control, CDC, Atlanta, Georgia
}

\begin{abstract}
Problem/Condition: In 2013, more than 57,000 persons died in the United States as a result of violence-related injuries. This report summarizes data from CDC's National Violent Death Reporting System (NVDRS) regarding violent deaths from 17 U.S. states for 2013. Results are reported by sex, age group, race/ethnicity, marital status, location of injury, method of injury, circumstances of injury, and other selected characteristics.
\end{abstract}

Reporting Period Covered: 2013.

Description of System: NVDRS collects data from participating states regarding violent deaths obtained from death certificates, coroner/medical examiner reports, law enforcement reports, and secondary sources (e.g., child fatality review team data, supplemental homicide reports, hospital data, and crime laboratory data). This report includes data from 17 states that collected statewide data for 2013 (Alaska, Colorado, Georgia, Kentucky, Maryland, Massachusetts, North Carolina, New Jersey, New Mexico, Ohio, Oklahoma, Oregon, Rhode Island, South Carolina, Utah, Virginia, and Wisconsin). NVDRS collates documents for each death and links deaths that are related (e.g., multiple homicides, a homicide followed by a suicide, or multiple suicides) from a single incident.

Results: For 2013, a total of 18,765 fatal incidents involving 19,251 deaths were captured by NVDRS in the 17 states included in this report. The majority (66.2\%) of deaths were suicides, followed by homicides $(23.2 \%)$, deaths of undetermined intent $(8.8 \%)$, deaths involving legal intervention (1.2\%) (i.e., deaths caused by law enforcement and other persons with legal authority to use deadly force, excluding legal executions), and unintentional firearm deaths $(<1 \%)$. (The term legal intervention is a classification incorporated into the International Classification of Diseases, Tenth Revision [ICD-10] and does not denote the lawfulness or legality of the circumstances surrounding a death caused by law enforcement.) Suicides occurred at higher rates among males, non-Hispanic whites, American Indian/Alaska Natives, persons aged 45-64 years, and males aged $\geq 75$ years. Suicides were preceded primarily by a mental health, intimate partner, or physical health problem or a crisis during the previous or upcoming 2 weeks. Homicide rates were higher among males and persons aged 15-44 years; rates were highest among non-Hispanic black males. Homicides primarily were precipitated by arguments and interpersonal conflicts, occurrence in conjunction with another crime, or were related to intimate partner violence (particularly for females). A known relationship between a homicide victim and a suspected perpetrator was most likely either that of an acquaintance or friend or an intimate partner. Legal intervention death rates were highest among males and persons aged 20-24 years and 30-34 years; rates were highest among non-Hispanic black males. Precipitating factors for the majority of legal intervention deaths were another crime, a mental health problem, or a recent crisis. Deaths of undetermined intent occurred at the highest rates among males and persons aged $<1$ year and $45-54$ years. Substance abuse and mental or physical health problems were the most common circumstances preceding deaths of undetermined intent. Unintentional firearm death rates were higher among males, non-Hispanic whites, and persons aged persons aged 15-19 and 55-64 years; these deaths were most often precipitated by a person unintentionally pulling the trigger while playing with a firearm or while hunting.

Interpretation: This report provides a detailed summary of data from NVDRS for 2013. The results indicate that violent deaths resulting from self-inflicted or interpersonal violence disproportionately affected persons aged $<65$ years, males, and certain minority populations. For homicides and suicides, intimate partner problems, interpersonal conflicts, mental health problems, and recent crises were primary precipitating factors.

Corresponding author: Bridget $\mathrm{H}$. Lyons, Division of Violence Prevention, National Center for Injury Prevention and Control, CDC. Telephone: 770-488-1721; E-mail: blyons@cdc.gov.
Public Health Action: NVDRS data are used to monitor the occurrence of violence-related fatal injuries and assist public health authorities in the development, implementation, and evaluation of programs and policies to reduce and prevent violent deaths. For 
example, Utah Violent Death Reporting System (VDRS) data were used to develop policies that support children of intimate partner homicide victims, Colorado VDRS data to develop a web-based suicide prevention program targeting middle-aged men, and Rhode Island VDRS data to help guide suicide prevention efforts at workplaces. The continued development and expansion of NVDRS to include all U.S. states, territories, and the District of Columbia are essential to public health efforts to reduce the impact of violence.

\section{Introduction}

In 2013, more than 57,000 persons died in the United States as a result of violence-related injuries (1). Suicide was the 10th leading cause of death overall in the United States and disproportionately affected young and middle-aged populations. It was among the top three leading causes of death for persons aged 10-34 years and among the top five for persons aged 35-54 years. American Indian/Alaska Natives were disproportionately affected by suicide; it was the second leading cause of death among those aged 10-34 years.

Homicide was the 16th leading cause of death overall in the United States but disproportionately affected young people (1). It was the third leading cause of death for children aged 1-4 years and persons aged 15-34 years, the fourth leading cause for children aged 5-9 years, and the fifth leading cause for persons aged 10-14 years and 35-44 years. Homicide disproportionately affected young African American males; it was the leading cause of death among those aged 15-34 years.

Public health authorities require accurate, timely, and comprehensive surveillance data to better understand and ultimately prevent the occurrence of violent deaths in the United States (2). In 2000, in response to an Institute of Medicine* report noting the need for a national fatal intentional injury surveillance system (3), CDC began planning to implement the National Violent Death Reporting System (NVDRS) (4). The goals are to

- collect and analyze timely, high-quality data for monitoring the magnitude and characteristics of violent deaths at national, state, and local levels;

- ensure data are disseminated routinely and expeditiously to public health officials, law enforcement officials, policymakers, and the public;

- ensure data are used to develop, implement, and evaluate programs and strategies that are intended to reduce and prevent violent deaths and injuries at national, state, and local levels; and

\footnotetext{
${ }^{*}$ The name of the Institute of Medicine was changed to the National Academy of Medicine, effective July 1, 2015.
}

- build and strengthen partnerships among organizations and communities at national, state, and local levels to ensure that data are collected and used to reduce and prevent violent deaths and injuries.

NVDRS was conceived as a state-based active surveillance system that would collect data on the characteristics and circumstances associated with all violence-related deaths in participating states. Deaths would include homicides, suicides, legal intervention deaths (i.e., deaths caused by law enforcement and other persons with legal authority to use deadly force but excluding legal executions), unintentional firearm deaths, and deaths of undetermined intent. ${ }^{\dagger}$ The term legal intervention is a classification incorporated into the International Classification of Diseases, Tenth Revision (ICD-10) and does not denote the lawfulness or legality of the circumstances surrounding a death caused by law enforcement. NVDRS data are used to assist the development, implementation, and evaluation of programs and strategies designed to reduce and prevent these deaths at the national, state, and local levels.

Before implementation of NVDRS, single data sources (e.g., death certificates or law enforcement reports) provided only limited information and few circumstances from which to understand patterns of violent deaths. NVDRS fills this surveillance gap by providing more detailed information. It is the first system to 1 ) provide detailed information on circumstances precipitating violent deaths, 2) link multiple source documents on violent deaths so that each incident can contribute to the study of patterns of violent deaths, and 3) link multiple deaths that are related to one another (e.g., multiple homicides, suicide pacts, or homicide followed by the suicide of the suspected perpetrator).

In 2003, NVDRS began data collection with seven states (Alaska, Maryland, Massachusetts, New Jersey, Oregon, South Carolina, and Virginia) participating; six states (Colorado, Georgia, North Carolina, Oklahoma, Rhode Island, and Wisconsin) joined in 2004, four (California, Kentucky, New Mexico, and Utah) in 2005, and two (Ohio and Michigan) in 2010 (Figure). CDC provides funding for state participation, and the ultimate goal is for NVDRS to expand to include all 50 states, U.S. territories, and the District of Columbia. ${ }^{\$}$

\footnotetext{
${ }^{\dagger}$ To be included in NVDRS, deaths of undetermined intent must have some evidence of the possibility that the intent was purposeful, including use of a weapon or other evidence that force was used to inflict the injury. Most commonly, the coroner/medical examiner is unsure whether the death was a suicide or unintentional.

\$In 2014, Arizona, Connecticut, Hawaii, Iowa, Illinois, Indiana, Kansas, Maine, Minnesota, New Hampshire, New York, Pennsylvania, Vermont, and Washington joined the system for a total of 32 states participating. These 14 states did not report data until 2015.
} 
FIGURE. States participating* in the National Violent Death Reporting System, by year of initial data collection, United States, 2003-2013

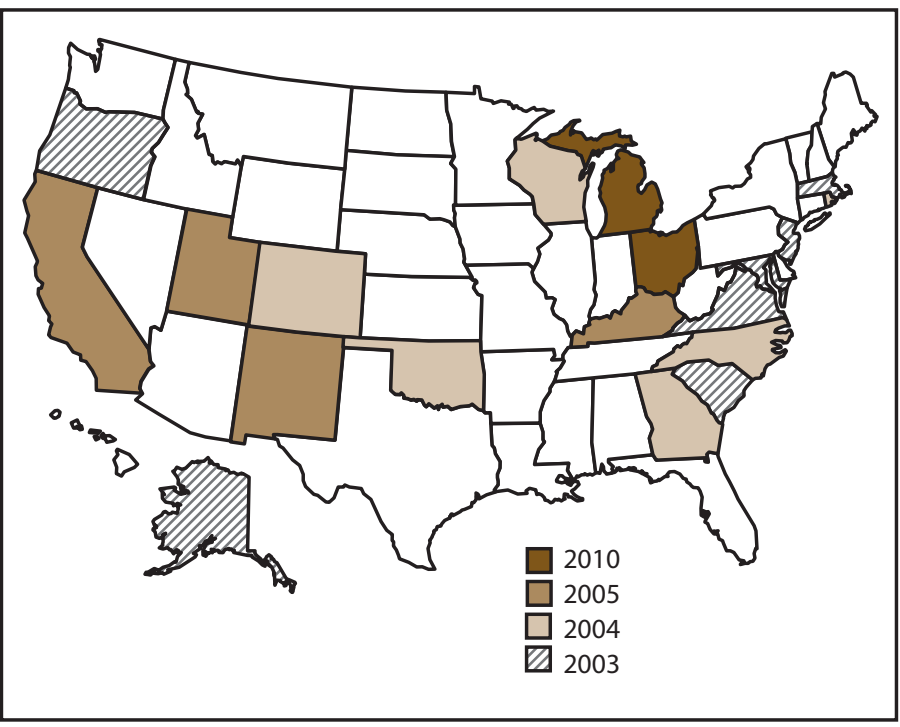

* California concluded participation in 2009. Michigan did not collect data statewide during 2013. These two states are excluded from the analysis in this report.

This report summarizes data for 2013 for deaths meeting NVDRS inclusion criteria from the 17 states that collected statewide data in that year (Alaska, Colorado, Georgia, Kentucky, Maryland, Massachusetts, New Jersey, New Mexico, North Carolina, Ohio, Oklahoma, Oregon, Rhode Island, South Carolina, Utah, Virginia, and Wisconsin); these states account for approximately $30.1 \%$ of the U.S. population $(1,5)$. The analysis in this report does not include data from California, which concluded its participation in 2009, and Michigan, which did not collect data statewide during 2013. NVDRS data are updated annually and are available through CDC's Web-based Injury Statistics Query and Reporting System (WISQARS) at http://www.cdc.gov/injury/wisqars/nvdrs.html.

\section{Methods}

NVDRS compiles information from multiple data sources. The core required data sources are death certificates, coroner/ medical examiner reports, and law enforcement reports. Some participating states also collect information from secondary sources (e.g., child fatality review team data, supplemental homicide reports, and crime laboratory data). NVDRS collates

\footnotetext{
9 Frequencies and rates of violent deaths included in this report will differ slightly from the frequencies and rates of violent deaths reported by NVDRS WISQARS, which excludes nonresident deaths that occur in participating states (i.e., occurrent deaths). NVDRS tracks both resident and occurrent violent deaths in the overall data set, and the numbers in this report reflect both.
}

documents for each death and links deaths that are related (e.g., multiple homicides, a homicide followed by a suicide, or multiple suicides) from a single incident. The ability to analyze linked data permits comprehensive assessment of violent deaths. This report presents data for 2013. Historical data and rates for 2011 and 2012 are available at https://stacks. cdc.gov/view/cdc/40576.

In NVDRS, a violent death is defined as a death resulting from the intentional use of physical force or power, threatened or actual, against oneself, another person, or a group or community. Information also is collected about unintentional firearm deaths (i.e., incidents in which the person causing the fatal injury did not intend to discharge the firearm) and deaths of undetermined intent (i.e., a death that results from the use of force or power against oneself or another person for which the evidence indicating one manner of death is no more compelling than evidence indicating another). NVDRS cases are coded on the basis of the International Classification of Diseases, Tenth Revision (ICD-10) (6) or on the basis of the manner of death assigned by the coroner/medical examiner, or law enforcement. Cases are included if they are assigned ICD-10 codes (Box 1) or if the manner of death specified in at least one of the three primary data sources is consistent with NVDRS case definitions.

Variables analyzed in NVDRS include

- manner of death (i.e., the intent [homicide/legal intervention, suicide, unintentional, undetermined] of the person inflicting a fatal injury);

- mechanism of injury (i.e., the method used to inflict a fatal injury) (Box 2);

- toxicology findings (i.e., for decedents who were tested);

- circumstances preceding injury (i.e., the events that preceded and were identified by investigators as relevant and therefore might have contributed to the infliction of a fatal injury) (Box 3);

- whether the decedent was a victim (i.e., a person who died as a result of a violence-related injury) or both a suspect and a victim (i.e., a person believed to have inflicted a fatal injury on a victim who then was fatally injured, such as the perpetrator of a homicide-suicide);

- information about suspects (i.e., a person believed to have inflicted a fatal injury on a victim);

- incident (i.e., an occurrence in which one or more persons sustained a fatal injury that was linked to a common event or perpetrated by the same suspect during a 24-hour period); and

- type of incident (i.e., a combination of the manner of death and the number of victims in an incident). 
Surveillance Summaries

BOX 1. International Classification of Diseases, Tenth Revision (ICD-10) codes used in the National Violent Death Reporting System

\begin{tabular}{|lll|}
\hline Manner of death & Death $\leq \mathbf{1}$ year after injury & Death $>$ 1 year after injury \\
\hline Intentional self-harm (suicide) & X60-X84 & Y87.0 \\
Assault (homicide) & X85-X99, Y00-Y09 & Y87.1 \\
Event of undetermined intent & Y10-Y34 & Y87.2, Y89.9 \\
Unintentional exposure to inanimate mechanical & W32-W34 & Y86 determined to be attributable \\
forces (firearms) & to firearms \\
Legal intervention (excluding executions, Y35.5) & Y35.0-Y35.4, Y35.6-Y35.7 & Y89.0 \\
Terrorism & U01, U03 & U02 \\
\hline
\end{tabular}

BOX 2. Methods used to inflict injury - National Violent Death Reporting System, 17 states, 2013

- Firearm: method that uses a powder charge to fire a projectile

- Hanging/strangulation/suffocation: hanging by the neck, manual strangulation, or plastic bag over the head

- Poisoning: street drug, alcohol, pharmaceutical, carbon monoxide, gas, rat poison, or insecticide

- Sharp instrument: knife, razor, machete, or pointed instrument (e.g., chisel or broken glass)

- Blunt instrument: club, bat, rock, or brick

- Fall: being pushed or jumping

- Motor vehicle: car, bus, motorcycle, or other transport vehicle

- Personal weapons: hands, feet, or fists

- Drowning: inhalation of liquid in bathtub, lake, or other source of water/liquid

- Fire/burns: inhalation of smoke or the direct effects of fire or chemical burns

- Intentional neglect: starvation, lack of adequate supervision, or withholding of health care

- Other: any method other than those already listed

- Unknown: method not reported or not known

NVDRS is an incident-based system, and all decedents associated with a given incident are grouped in one record. Decisions about whether two or more deaths are related and belong to the same incident are made on the basis of the timing of the injuries rather than on the timing of the deaths. Deaths that occur within 24 hours of each other (i.e., the 24-hour rule) and are linked by source documents would be considered part of the same incident. Examples of an incident include 1) a single isolated violent death, 2) two or more related homicides (including legal intervention deaths) when the fatal injuries were inflicted $<24$ hours apart, 3 ) two or more related suicides or deaths of undetermined intent when the fatal injuries were inflicted $<24$ hours apart, and 4 ) a homicide followed by a suicide when both fatal injuries were inflicted $<24$ hours apart (7).

Data collected from individual information sources are entered into the NVDRS web-based data entry system (8). In 2013, NVDRS began using a streamlined coding system to facilitate data abstraction efficiency by eliminating the need to enter data into source-specific data entry screens. The streamlined interface allows data from multiple sources to be entered into the same incident record and includes internal validation checks, hover-over features that define selected fields, and other quality control measures. Primacy rules and hierarchal algorithms related to the source documents are now occurring at the state level. Access to the web system is provided to each state by CDC. State project personnel are provided coding training to help increase data quality. Data are transmitted continuously via the web to a CDC-based server. No personally identifiable information is transmitted to CDC.

\section{Manner of Death}

A manner (i.e., intent) of death for each decedent is assigned by a trained abstractor who assimilates information from all source documents. The manner of death assigned must be consistent with the manner of death noted in at least one source document. When there is a discrepancy, the abstractor must assign a manner of death on the basis of the preponderance of evidence in the source documents, but such occurrences are rare. For example, if two sources report a death as a suicide and a third reports it as a death of undetermined intent, the death is coded as a suicide.

NVDRS data are categorized into five abstractor-assigned manners of death: 1) suicide, 2) homicide, 3) unintentional firearm, 4) undetermined intent, and 5) legal intervention.

- Suicide. Suicide is a death resulting from the use of force against oneself when a preponderance of evidence indicates that the use of force was intentional. This category includes 


\section{Suicide/Undetermined Intent}

- Intimate partner problem: decedent was experiencing problems with a current or former intimate partner.

- Suicide of friend or family member: decedent was distraught over, or reacting to, a relatively recent suicide of a friend or family member.

- Other death of friend or family member: decedent was distraught over, or reacting to, a relatively recent nonsuicide death of a friend or family member.

- Physical health problem: decedent was experiencing physical health problems (e.g., a recent cancer diagnosis or chronic pain).

- Job problem: decedent was either experiencing a problem at work or was having a problem with joblessness.

- Recent criminal legal problem: decedent was facing a criminal legal problem.

- Noncriminal legal problem: decedent was facing a civil legal problem (e.g., a child custody or civil lawsuit).

- Financial problem: decedent was experiencing a problem such as bankruptcy, overwhelming debt, or foreclosure of a home or business.

- Eviction or loss of home: decedent was experiencing a recent eviction or other loss of housing.

- School problem: decedent was experiencing a problem such as poor grades, bullying, social exclusion at school, or performance pressures.

- Traumatic anniversary: the incident occurred on or near the anniversary of a traumatic event in the decedent's life.

- Exposure to disaster: decedent was exposed to a disaster (e.g., earthquake or bombing).

- Left a suicide note: decedent left a note, e-mail message, video, or other communication indicating intent to die by suicide.

- Disclosed intent to die by suicide: decedent had previously expressed suicidal feelings to another person with time for that person to intervene.

- History of suicidal thoughts or plans: decedent had previously expressed suicidal thoughts or plans.

- History of suicide attempt: decedent had previously attempted suicide before the fatal incident.

\section{Homicide/Legal Intervention}

- Jealousy (lovers' triangle): jealousy or distress over an intimate partner's relationship or suspected relationship with another person.

- Stalking: pattern of unwanted harassing or threatening tactics by either the decedent or suspect.

- Prostitution: prostitution or related activity that includes prostitutes, pimps, clients, or others involved in such activity.

- Drug involvement: drug dealing, drug trade, or illegal drug use.

- Brawl: mutual physical fight involving three or more persons.

- Mercy killing: decedent wished to die because of terminal or hopeless disease or condition, and documentation indicates that the decedent wanted to be killed.

- Victim was a bystander: decedent was not the intended target in the incident (e.g., pedestrian walking past a gang fight).

- Victim was a police officer on duty: decedent was a law enforcement officer killed in the line of duty.

- Victim was an intervener assisting a crime victim: decedent was attempting to assist a crime victim at the time of the incident (e.g., a child is killed while trying to assist a parent who is being assaulted).

- Victim used a weapon: decedent used a weapon to attack or defend against suspect during the course of the incident.

- Intimate partner violence-related: incident is related to conflict between current or former intimate partners; includes the death of intimate partners and nonintimate-partner victims (e.g., child or parent) killed to cause pain to an intimate partner.

- Hate crime: decedent was intentionally selected because of actual or perceived gender, religion, sexual orientation, race/ethnicity, or disability.

- Mentally ill suspect: suspect's attack on decedent was believed to be the direct result of a mental illness.

- Drive-by shooting: suspect drove near and shot the decedent.

- Walk-by assault: decedent was killed by a targeted attack (e.g., ambush) and the suspect fled on foot.

- Random violence: decedent was killed by a random act of violence.

- Gang-related: incident resulted from gang activity or gang rivalry; not used if the decedent was a gang member whose death did not appear to result from gang activity. 


\section{All Manners of Death (Except Unintentional Firearm)}

- Current depressed mood: decedent was perceived by self or others to be depressed.

- Current diagnosed mental health problem: decedent was identified as having a mental health disorder or syndrome listed in the Diagnostic and Statistical Manual, Version IV (DSM-IV), with the exception of alcohol and other substance dependence (these are captured in separate variables).

- Type of mental health diagnosis: identifies the DSM-IV diagnosis made by a medical or mental health practitioner.

- Current mental health treatment: decedent was currently receiving mental health treatment as evidenced by a current prescription for a psychotropic medication or visit to a mental health professional in the previous 2 months.

- History of treatment for mental health problem: decedent was identified as having ever received mental health treatment.

- Alcohol/other substance problem: decedent was perceived by self or others to have a problem with, or to be addicted to, alcohol or other drugs.

- Other addiction: decedent was perceived by self or others to have an addiction other than alcohol or other substance (e.g., gambling, sex).

- Family relationship problem: decedent was experiencing a problem with a family member, other than an intimate partner.

- Other relationship problem: decedent was experiencing a problem with a family member, friend, or associate (other than an intimate partner).

- History of child abuse/neglect: decedent had history of physical, sexual, or psychological abuse; physical, emotional, or educational neglect; or exposure to a violent environment or inadequate supervision by caretaker as a child.

- Caretaker abuse/neglect led to death: decedent was experiencing physical, sexual, or psychological abuse; physical, emotional, or educational neglect; or exposure to a violent environment or inadequate supervision by caretaker.

- Perpetrator of interpersonal violence in previous month: decedent perpetrated interpersonal violence during the previous month.
- Victim of interpersonal violence in previous month: decedent was the target of interpersonal violence in the past month.

- Physical fight: a physical fight between two individuals that resulted in the death of a person who was either involved in the fight, a bystander, or trying to stop the fight.

- Argument or conflict: a specific argument or disagreement occurred during the incident.

- Precipitated by another crime: incident occurred as the result of another serious crime.

- Nature of crime: identifies the crime that occurred during the incident (e.g., robbery or drug trafficking).

- Crime in progress: a serious crime was in progress at the time of the incident.

- Terrorist attack: decedent was injured during a terrorist attack.

- Crisis during previous or upcoming 2 weeks: decedent experienced a current crisis or acute precipitating event that had either occurred in the previous 2 weeks or was impending in the following 2 weeks (e.g., a trial for a criminal offense begins the following week).

- Other crisis: a crisis related to a death but not captured by any of the circumstances.

\section{Unintentional Firearm Death}

\section{Context of Injury}

- Hunting: death occurred any time after leaving home for a hunting trip and before returning home from a hunting trip.

- Target shooting: shooter was aiming for a target and unintentionally hit the decedent; can be at a shooting range or an informal backyard setting (e.g., teenagers shooting at signposts on a fence).

- Loading/unloading gun: gun discharged while the shooter was loading or unloading ammunition.

- Cleaning gun: shooter pulled trigger or gun discharged while cleaning, repairing, assembling, or disassembling gun.

- Showing gun to others: gun was being shown to another person when it discharged or the trigger was pulled.

- Playing with gun: shooter and one or more others were playing with a gun when it discharged.

- Celebratory firing: shooter fired gun in celebratory manner (e.g., on New Year's Eve).

- Other context of injury: shooting occurred during some context other than those already described. 


\section{Mechanism of Injury}

- Unintentionally pulled trigger: shooter unintentionally pulled the trigger (e.g., while grabbing the gun or holding it too tightly).

- Thought gun safety was engaged: shooter believed the safety was on and gun would not discharge.

- Thought unloaded/magazine disengaged: shooter believed the gun was unloaded because the magazine was disengaged.

- Thought gun was unloaded: shooter believed the gun was unloaded for other unspecified reason.

- Bullet ricochet: bullet ricocheted from the intended target and struck the decedent.
- Gun defect or malfunction: gun had a defect or malfunctioned, as determined by a trained firearm examiner.

- Gun fired while holstering: gun was being replaced or removed from a holster or clothing.

- Dropped gun: gun discharged when it was dropped or when something was dropped on it.

- Gun fired while operating safety/lock: shooter unintentionally fired the gun while operating the safety lock.

- Gun mistaken for toy: gun was mistaken for a toy and was fired without the shooter understanding the danger.

- Other mechanism of injury: shooting occurred as the result of a mechanism not already described. deaths of persons who intended only to injure rather than kill themselves, deaths associated with risk-taking behavior without clear intent to inflict fatal self-injury but associated with high risk for death (e.g., playing Russian roulette), and suicide involving another person providing only passive assistance to the decedent (e.g., supplying the means or information needed to complete the act). This category does not include deaths caused by chronic or acute substance abuse without the intent to die or deaths attributed to autoerotic behavior (e.g., self-strangulation during sexual activity). Corresponding ICD-10 codes included in NVDRS are X60-X84 and Y87.0 (Box 1).

- Homicide. Homicide is a death resulting from the use of physical force or power, threatened or actual, against another person, group, or community when a preponderance of evidence indicates that the use of force was intentional. Two special scenarios that the National Center for Health Statistics (NCHS) regards as homicides are included in the NVDRS case definition: 1) arson with no intent to injure a person and 2) a stabbing with intent unspecified. This category excludes vehicular homicide without intent to injure, unintentional firearm deaths (a separate category), combat deaths or acts of war, and deaths of unborn fetuses but includes acts of terrorism. Corresponding ICD-10 codes included in NVDRS are X85-X99, U01-U03, Y00-Y09, and Y87.1 (Box 1).

- Unintentional firearm. An unintentional firearm death is a death resulting from a penetrating injury or gunshot wound from a weapon that uses a powder charge to fire a projectile and for which a preponderance of evidence indicates that the shooting was not directed intentionally at the decedent. Examples include a person who dies as a result of celebratory firing that was not intended to frighten, control, or harm anyone; a soldier shot during a field exercise but not in a combat situation; a person who received a self-inflicted wound while playing with a firearm; and a person who mistakenly believes a gun is unloaded and shoots another person. This category excludes firearm injuries caused by unintentionally striking a person with the firearm (e.g., hitting a person on the head with the firearm rather than firing a projectile) and unintentional injuries from nonpowder guns (e.g., BB, pellet, or other compressed air-powered or gas-powered guns). Corresponding ICD-10 codes included in NVDRS are W32-W34 and Y86 (Box 1).

- Undetermined intent. A death of undetermined intent is a death resulting from the use of force or power against oneself or another person for which the evidence indicating one manner of death is no more compelling than evidence indicating another. This category includes coroner/medical examiner rulings (e.g., accident or suicide, undetermined, jumped or fell, or self-inflicted injury) when records give no evidence or opinions in favor of either unintentional or intentional injury. Corresponding ICD-10 codes in NVDRS are Y10-Y34, Y87.2, and Y89.9 (Box 1).

- Legal intervention. A death from legal intervention is a death in which a person is killed by a law enforcement officer or other peace officer (i.e., a person with specified legal authority to use deadly force), including military police, while on duty. The term legal intervention is a classification from ICD-10 codes and does not denote the lawfulness or legality of the circumstances surrounding the death. Legal intervention deaths include a small subset in which force was applied without clear lethal intent (e.g., during restraint or when applying force with a typically nondeadly weapon, such as a Taser [Taser International, Scottsdale, Arizona]) or in which the death occurred while the person was fleeing capture. This category excludes legal executions. 
Corresponding ICD-10 codes included in NVDRS are Y35.0-Y35.4, Y35.6-Y35.7, and Y89.0 (Box 1).

\section{Variables Analyzed}

NVDRS collects approximately 300 unique variables for each death. The number of variables recorded for each incident depends on the content and completeness of the source documents. Variables include manner of death; demographic information; ICD-10 cause of death codes and text descriptors; location, date, and time of injury and death; toxicology results; bodily injuries; precipitating circumstances; victim-suspect relationship; and method of injury (Box 1) (Box 2) (Box 3).

\section{Circumstances Preceding Death}

The circumstances preceding death are defined as the precipitating events that contributed to the infliction of a fatal injury (Box 3). The circumstances are reported on the basis of the content of the coroner/medical examiner and law enforcement investigative reports. Some circumstances are coded to a specific manner of death (e.g., suicide or death of undetermined intent); other circumstances are coded across all manners of death. The data abstractor selects from a list of potential circumstances and is required to code all circumstances known that relate to each incident. If circumstances are not known (e.g., for a body found in the woods with no other details reported) the data abstractor leaves the circumstances known variable blank; these deaths are excluded from the denominator for circumstance values. If either the coroner/medical examiner record or the law enforcement report indicates the presence of a circumstance, then the abstractor endorses the circumstance (e.g., if the law enforcement report indicated that a decedent had disclosed an intent to commit suicide, then suicidal intent is endorsed).

\section{Coding Training and Quality Control}

Ongoing coding support for data abstractors is provided through an e-mail help desk, monthly conference calls with all states, and regular conference calls with individual states. States can also conduct additional abstractor training workshops and activities at their own discretion. An NVDRS coding manual with CDC-issued standard guidance on coding criteria and examples for each data element is provided. Software features to enhance coding reliability include automated validation rules and a hoverover feature containing variable-specific information.

States are requested to perform annual blind reabstractions of a subset of cases using multiple abstractors to identify inconsistencies. CDC also runs a quality control analysis in which multiple variables are reviewed for their appropriateness, with special focus on abstractor-assigned variables (e.g., method and manner of death). If CDC finds inconsistencies, the state is notified and asked for a response or correction.

\section{Time Frame}

States are required to report all deaths within 6 months of the end of each calendar year for the preceding JanuaryDecember. States then have an additional 12 months to complete each incident record. Although states typically meet these requirements, additional details sometimes arrive after a deadline has passed. New incidents also might be identified after the deadline (e.g., a death certificate is revised, new evidence is obtained that changes a manner of death, or an ICD-10 miscoding is corrected to meet NVDRS inclusion criteria). These additional data are incorporated into NVDRS. CDC estimates that case counts might increase 1.0\%-2.0\% after the 18-month data collection period.

\section{Fatal Injuries in 2013}

This report provides data concerning fatal injuries meeting the NVDRS case definition for violent deaths in 2013 for 17 participating states that were received by CDC as of October 5, 2015. Participating states used vital statistics death certificate files or coroner/medical examiner reports to identify violent deaths meeting NVDRS case definitions. Each state reported all violent deaths of residents that occurred within the state and those of nonresidents for whom a fatal injury occurred within the state (i.e., occurrent deaths). Once a violent death was identified, NVDRS data abstractors linked source documents, linked deaths within each incident, coded data elements, and wrote a short narrative of the incident. State-level data were then consolidated and analyzed for this aggregate report.

Numbers, percentages, and crude rates are presented in aggregate for all deaths by abstractor-assigned manner of death. Rates for cells with frequency $<20$ are not reported because of the instability of those rates (9). Rates could not be calculated for some variables (e.g., marital status and precipitating circumstances) because denominators were unknown. Bridgedrace 2013 population estimates were used as denominators in the crude rate calculations (10). For compatible numerators for rate calculations to be derived, records listing multiple races were recoded to a single race, when possible, using racebridging methods described by NCHS (available at http:// www.cdc.gov/nchs/nvss/bridged_race.htm). 


\section{Results}

\section{All Deaths Captured by NVDRS}

\section{Deaths by Manner, Method, and Location}

The 17 NVDRS states included in this report collected data concerning 18,765 incidents and 19,251 deaths that occurred in 2013. The crude death rate was 20.1 deaths per 100,000 population. Suicides ( $\mathrm{n}=12,747 ; 66.2 \%$ of total) accounted for the highest rate of violent deaths (13.3 per 100,000 population), followed by homicides ( $n=4,459 ; 23.2 \%$ of total) (4.6 per 100,000 population). Deaths of undetermined intent $(\mathrm{n}=1,698 ; 8.8 \%$ of total), legal intervention deaths $(\mathrm{n}=222$; $<1.0 \%$ of total), and unintentional firearm deaths $(\mathrm{n}=125$; $<1.0 \%$ of total) occurred at lower rates $(1.8,0.2$, and 0.1 per 100,000 population, respectively). Firearms were the method used in $51.3 \%$ of deaths, hanging/strangulation/suffocation in $17.2 \%$, and poisoning in $16.3 \%$ (rates: $10.3,3.4$, and 3.3 per 100,000 population, respectively). Rates for all other methods were lower. For all deaths, a house or apartment was the most common location where injury occurred (69.4\%), followed by a street or highway $(6.4 \%)$ (Table 1 ).

\section{Toxicology Results of Decedent}

Tests for alcohol were conducted for $59.2 \%$ of decedents and tests for amphetamines, antidepressants, benzodiazepines, cocaine, marijuana, and opiates were conducted for 35.6\%, $28.7 \%, 35.1 \%, 38.8 \%, 30.6 \%$, and $42.2 \%$, respectively (Table 2). Among the $37.6 \%$ of tested decedents with positive results for alcohol, $67.8 \%$ had blood alcohol concentration $(B A C) \geq 0.08 \mathrm{~g} / \mathrm{dL}$ (i.e., over the legal limit in all states). Opiates, including heroin and prescription pain medications, were identified in $31.8 \%$ of decedents tested for these substances, amphetamines in $9.2 \%$, antidepressants in $33.2 \%$, benzodiazepines in $29.0 \%$, cocaine in $10.4 \%$, and marijuana in $24.0 \%$ (Table 2). The other drugs/substances category includes over-the-counter drugs (e.g., diphenhydramine, a common antihistamine), nicotine, or other substances not otherwise categorized (e.g., hypnotics, tranquilizers, or other analgesics). Ninety-nine percent of decedents tested for other drugs/substances had positive results. The explanation for the high percentage of positive toxicology test results is believed to be twofold (1): Positive results 1) might indicate miscellaneous other substances that investigators had a reason to test for, given a decedent's history, and 2) might indicate additional substances that were reported in a comprehensive exploratory toxicology panel.

\section{Suicides}

\section{Sex, Race/Ethnicity, Age Group, and Marital Status}

The 17 NVDRS states included in this report collected data for 2013 concerning 12,729 suicide incidents, which included 12,747 deaths (Table 1). Rates of suicide by month of death varied little throughout the year (range: $1.0-1.2$ per 100,000 population) (Table 3 ). Overall, the crude suicide rate was 13.3 per 100,000 population (Table 3 ). The rate for males was nearly four times the rate for females (21.0 and 5.9 per 100,000 population, respectively) (Table 4). Non-Hispanic American Indian/Alaska Natives and non-Hispanic whites had the highest rates of suicides (18.7 and 16.4 per 100,000 population, respectively). The highest rates of suicide by age group occurred among persons aged 45-54 years, 55-64 years, and $\geq 85$ years $(19.8,18.4$, and 17.3 per 100,000 population, respectively). Persons aged 10-14 years had the lowest rate of suicide among all age groups (2.0 per 100,000 population). The suicide rate among persons aged 15-19 years (8.6 per 100,000 population) was approximately half of that for persons aged 35-64 years.

Decedents aged 35-64 years accounted for more than half $(52.6 \%)$ of suicides among males. Rates among males were highest for men aged $\geq 85$ years, followed by men aged $75-84$ and $45-54$ years $(45.5,33.0$, and 29.6 per 100,000 population, respectively). Non-Hispanic whites (25.8 per 100,000 population) and non-Hispanic American Indian/Alaska Natives (30.2 per 100,000 population) had the highest rates of any male subgroups; these rates were more than three times the rate for males with the lowest rate, Asian/Pacific Islanders (8.2 per 100,000 population). Decedents aged 35-64 years accounted for the majority (60.9\%) of suicides among females. The rate among females was highest for women aged 45-54 years (10.3 per 100,000). Non-Hispanic American Indian/Alaska Natives (7.7 per 100,000 population) and non-Hispanic whites (7.3 per 100,000 population) had the lowest suicide rates among females; rates were lowest among Asian/Pacific Islanders (2.5 per 100,000 population) and non-Hispanic blacks ( 2.0 per 100,000 population). Of suicide decedents aged $\geq 18$ years, $34.5 \%$ were married, $29.7 \%$ had never married, and $21.6 \%$ were divorced at the time of death (Table 4).

\section{Method and Location of Injury}

Firearms were used in more than half of suicides (51.4\%), followed by hanging/strangulation/suffocation (24.5\%) and poisoning (15.5\%) (rates: 6.8, 3.2, and 2.1 per 100,000 population, respectively) (Table 3 ). Among males, the most common method used was a firearm $(56.9 \%)$ followed by hanging/strangulation/suffocation (24.7\%) (Table 5). Among 
females, poisoning was the most common method used (34.6\%), followed by a firearm (32.4\%). The most common place of suicide was a house or apartment $(75.2 \%)$, followed by a natural area $(4.6 \%)$, a motor vehicle $(4.6 \%)$, and a hotel/ motel $(2.1 \%)$. A total of $173(1.4 \%)$ suicides occurred in a jail/prison (152 males and 21 females).

\section{Toxicology Results of Decedent and Precipitating Circumstances}

Tests for alcohol were conducted for $55.9 \%$ of suicide decedents and tests for amphetamines, antidepressants, benzodiazepines, cocaine, marijuana, and opiates were conducted for $34.2 \%, 28.4 \%, 33.9 \%, 36.3 \%, 28.9 \%$, and $38.3 \%$, respectively (Table 6). Among those with positive results for alcohol (38.2\%), 70.3\% had BAC $\geq 0.08 \mathrm{~g} / \mathrm{dL}$. Opiates, including heroin and prescription pain medications, were identified in $26.8 \%$ of decedents tested for these substances; cocaine and marijuana were identified in 5.8\% and $16.6 \%$ of decedents tested, respectively. Of those tested for antidepressants, $35.3 \%$ had positive results at the time of their death (Table 6).

Precipitating circumstances were known for $88.5 \%$ of suicides. Overall, mental health problems were the most common circumstance; $38.3 \%$ of decedents were described as experiencing a depressed mood at the time of their death, $46.2 \%$ as having a current diagnosed mental health problem, and $32.1 \%$ as receiving mental health treatment (Table 7). Among the 5,204 decedents with a current diagnosed mental health problem, depression/dysthymia $(72.8 \%)$, anxiety disorder (15.4\%), and bipolar disorder (13.8\%) were the most common diagnoses for males and females (Table 8).

Substantial percentages of female (40.5\%) and male (37.7\%) decedents were reported to have a depressed mood at the time of their suicide and $62.7 \%$ of females and $41.2 \%$ of males were reported to have a current diagnosed mental health problem. The percentages of females $(47.0 \%)$ and males $(27.6 \%)$ receiving treatment for a mental health problem were lower (Table 7).

Among 11,267 suicides with known circumstances, 34.8\% of decedents left a suicide note, $32.4 \%$ had a history of suicidal thoughts or plans, $19.7 \%$ had a history of previous suicide attempts, and $25.7 \%$ had disclosed suicidal intent to another person (Table 7). The majority of decedents disclosed intent to a previous or current intimate partner $(37.7 \%)$ or to some other family member (29.8\%). Alcohol or other substance abuse problems were indicated for $18.3 \%$ and $16.3 \%$ of suicide decedents, respectively. Other common circumstances were a crisis in the preceding or upcoming 2 weeks (32.3\%) and intimate partner problems (29.7\%). Physical health problems (21.6\%), an argument or conflict (16.2\%), and job or financial problems ( $12.4 \%$ and $11.0 \%$, respectively) were also reported to have preceded suicides.

Slightly more than one-fifth of male $(21.4 \%)$ and female $(22.3 \%)$ decedents experienced physical health problems that contributed to their suicide (Table 7). Job problems were noted as a precipitating circumstance in a higher percentage of males than females (13.6\% and $8.3 \%$, respectively), as were financial problems ( $11.7 \%$ and $8.5 \%)$, recent criminal legal problems $(10.4 \%$ and $5.2 \%)$, and intimate partner problems $(31.2 \%$ and $25 \%)$. In contrast, family (nonintimate) relationship problems were a precipitating circumstance in a higher percentage of females than males (12.3\% and 8.8\%, respectively). Although indicated in a relatively small percentage of suicides, among males being a perpetrator of interpersonal violence in the month before death was more common (3.7\%) than being a victim of such violence $(<1.0 \%)$; among females, the percentages were similar (1.0\% and $1.2 \%$, respectively) (Table 7$)$.

Among suicide decedents for whom a crisis in the previous or upcoming 2 weeks was reported, intimate partner problems (42.9\%), criminal legal problems (13.7\%), and physical health problems $(12.7 \%)$ were most common (Table 9). These percentages are similar to those for the most common precipitating circumstances.

\section{Homicides/Legal Intervention Deaths}

\section{Sex, Race/Ethnicity, Age Group, and Marital Status}

The 17 NVDRS states included in this report collected data concerning 4,448 homicide/legal intervention incidents, which included 4,681 deaths in 2013 (Table 10). Rates of homicides by month of death varied little throughout the year (range: $0.3-0.5$ per 100,000 population). Overall, the crude homicide rate was 4.9 deaths per 100,000 population. The majority of homicide decedents aged $\geq 18$ years $(55.5 \%)$ had never been married, and $20.0 \%$ were married at the time of their death (Table 11$)$. In more than half $(52.8 \%)$ of homicides, the relationship of the victim to the suspect was not known; when the relationship was known, the suspect most often was an acquaintance or friend $(22.6 \%)$, a spouse or intimate partner $(21.0 \%)$, or a stranger $(12.1 \%)$.

The homicide rate for males was three and half times the rate for females (7.7 and 2.2 per 100,000 population, respectively) (Table 12). Non-Hispanic blacks accounted for more than half $(52.7 \%)$ of homicides and had the highest rate (16.7 per 100,000 population), followed by American Indian/Alaska Natives (7.7 per 100,000 population) and Hispanics (4.4 per 100,000 population). Non-Hispanic black males had the highest rate of homicide deaths among males of any other race/ethnicity (29.8 per 100,000 population). Age-specific 
homicide rates were highest (12.1 per 100,000 population) among persons aged 20-24 years, followed by persons aged 25-29 years (10.1 per 100,000 population). The rate for infants aged $<1$ year was more than three times the rate for children aged $1-4$ years ( 7.6 and 2.1 per 100,000 population, respectively). Rates were lowest among persons aged 5-14 years and 65-84 years. Among males, the majority of homicide decedents $(55.8 \%)$ were aged $15-34$ years; the rate was highest among men aged $20-24$ years (20.4 per 100,000 population). Among females, the homicide rate was highest (5.9 per 100,000 population) among infants aged $<1$ year. The rate among male infants aged $<1$ year was 9.3 per 100,000 population.

\section{Method and Location of Injury}

Firearms were used in $66.6 \%$ of homicides, followed by sharp instruments (11.1\%), blunt instruments (5.6\%), and personal weapons (e.g., hands, feet, fists) (4.7\%) (Table 10). No other method was used in more than $4.0 \%$ of homicides. Firearms were the most common method used in homicides of males (71.8\%) and females (48.8\%) (Table 13). Hanging/ strangulation/suffocation was more common among females $(8.8 \%)$ than males $(1.7 \%)$, as was use of blunt instruments (7.5\% and $5.1 \%$, respectively). A house or apartment was the most common location of homicide $(51.9 \%$; males and females $45.7 \%$ and $73.4 \%$, respectively), followed by a street or highway (19.9\%); a motor vehicle (6.7\%); or a parking lot, a public garage, or public transport (3.9\%) (Table 13).

\section{Toxicology Results of Decedent and Precipitating Circumstances}

Tests for alcohol were conducted for $61.8 \%$ of homicide decedents and tests for amphetamines, antidepressants, benzodiazepines, cocaine, marijuana, and opiates were conducted for $38.0 \%, 23.0 \%, 33.2 \%, 42.3 \%, 34.8 \%$, and $41.3 \%$, respectively (Table 14). Among those who had positive results for alcohol (38.1\%), 63.6\% had BAC $\geq 0.08 \mathrm{~g} / \mathrm{dL}$. Marijuana, opiates, and cocaine were identified in $42.5 \%$, $18.3 \%$, and $15.7 \%$ of homicide decedents tested, respectively (Table 14).

Precipitating circumstances were identified for $78.5 \%$ of homicides. Approximately one in three of those homicides were precipitated by another crime (Table 15); in 69.9\% the crime was in progress at the time of the incident. The type of crime most frequently precipitating the homicide was assault/ homicide $(44.3 \%)$, followed by robbery $(34.2 \%)$, burglary (13.1\%), drug trade** $(11.4 \%)$, rape/sexual assault (2.9\%), motor vehicle theft $(2.8 \%)$, and arson (1.3\%) (Table 16).

\footnotetext{
** Drug trade is defined as the buying, selling, or passing of drugs in exchange for goods or money. Drug involvement includes drug use in addition to drug trade.
}

Other common precipitating circumstances were an argument or conflict $(33.2 \%)$, drug involvement $(12.7 \%)$, or victim's use of a weapon (9.6\%). In $18.8 \%$ of homicides with known circumstances, intimate partner violence was identified as a contributing factor (Table 15).

An argument or a conflict was a factor in more homicides among males $(34.5 \%)$ than among females (29.3\%). Drug involvement accounted for $15.2 \%$ of homicides among males and $5.3 \%$ among females. Intimate partner violence was a precipitating factor in $47.5 \%$ of homicides among females but only $9.3 \%$ among males. Male decedents also used a weapon during the incident in $12.1 \%$ and female decedents in $2.2 \%$ of homicides with known circumstances (Table 15).

Information was collected on crises experienced by decedents within the previous or upcoming 2 weeks (Table 17). The most common crises precipitating homicides were family relationship problems $(22.5 \%)$ and jealousy (e.g., lovers' triangle) (16.3\%).

\section{Legal Intervention Deaths}

The 17 NVDRS states included in this report collected data concerning 222 legal intervention incidents, which included 222 deaths in 2013 (Table 18). When analyzed separately from homicides, the majority of legal intervention deaths occurred among males (93.7\%), with the highest rate among men aged 30-34 (1.1 per 100,000 population). Non-Hispanic white males accounted for the highest percentage of legal intervention deaths (43.8\%), but non-Hispanic black males had the highest rate (1.2 per 100,000 population), four times the rate for nonHispanic white males $(0.3$ per 100,000$)$. Firearms were used in almost all legal intervention deaths (92.3\%) (Table 19). Legal intervention deaths occurred most frequently in a house or apartment (41.4\%), followed by a street or highway (25.2\%) and a motor vehicle (8.6\%) (Table 19).

Tests for alcohol were conducted for $72.1 \%$ of legal intervention decedents and tests for amphetamines, antidepressants, benzodiazepines, cocaine, marijuana, and opiates were conducted for 46.4\%, 33.8\%, 53.2\%, 59.0\%, $43.2 \%$, and $59.0 \%$, respectively (Table 20). Among those who had positive results for alcohol (39.4\%), 76.2\% had BAC $\geq 0.08 \mathrm{~g} / \mathrm{dL}$. Opiates, including heroin and prescription pain medications, were identified in $18.3 \%$ of those tested for these substances; cocaine and marijuana were identified in $15.3 \%$ and $37.5 \%$, respectively. Of legal intervention decedents who were tested for antidepressants, $22.7 \%$ had positive results at the time of their death (Table 20).

Precipitating circumstances were identified for $98.2 \%$ of legal intervention deaths. Approximately $87.6 \%$ were precipitated by another crime (Table 21 ); in $74.3 \%$ of those the crime was in progress at the time of the incident. The type of crime 
most frequently precipitating the legal intervention death was assault/homicide $(68.1 \%)$, followed by robbery $(9.9 \%)$, motor vehicle theft (5.2\%), and burglary (4.7\%) (Table 22). Other common precipitating circumstances were an argument or conflict $(14.2 \%)$ or drug involvement $(7.8 \%)$. In $10.6 \%$ of legal intervention deaths with known circumstances, intimate partner violence was identified as a contributing factor (Table 21). The decedent reportedly used a weapon in $72.5 \%$ of legal intervention deaths (Table 21). A recent crisis within the previous or upcoming 2 weeks was cited in $16.6 \%$ of legal intervention deaths (Table 23). The two most common crisis circumstances were family relationship problems $(16.2 \%)$ and current diagnosed mental health problems (10.8\%).

\section{Deaths of Undetermined Intent}

\section{Sex, Race/Ethnicity, Age Group, and Marital Status}

The 17 NVDRS states included in this report collected data concerning 1,688 incidents involving 1,698 deaths in 2013 for which a determination of intent could not be made (Table 24). Rates of deaths of undetermined intent varied little by month of death (range: $0.1-0.2$ per 100,000 population) throughout the year. Overall, the crude rate of deaths of undetermined intent was 1.8 per 100,000 population. Rates were higher among males than among females ( 2.3 and 1.3 per 100,000 population, respectively) (Table 25). Non-Hispanic whites accounted for $78.2 \%$ of deaths of undetermined intent and also had the highest rate (2.0 per 100,000 population). Non-Hispanic white males had the highest rate of death of undetermined intent (2.5 per 100,000 population) compared with males or females of any other race/ethnicity. More than half $(59.6 \%)$ of persons for whom the manner of death was undetermined were aged 35-64 years. Rates were highest (3.2 per 100,000 population) among infants aged $<1$ year and adults aged $45-54$ years. Among decedents aged $\geq 18$ years for whom intent of death was undetermined, $40.9 \%$ never had been married, $23.8 \%$ were married, and $24.9 \%$ were divorced at the time of death (Table 25).

\section{Method and Location of Injury}

The most common method of injury in deaths of undetermined intent was poisoning (67.4\%) (Table 26). No other method accounted for $>5.0 \%$ overall. The majority of deaths of undetermined intent occurred in a house or apartment $(73.9 \%)$. A house or apartment was the most common place of injury for males and females $(70.8 \%$ and $79.1 \%$, respectively), followed by a street or highway (4.3\% and $3.2 \%)$.

\section{Toxicology Results of Decedent and Precipitating Circumstances}

Tests for alcohol were conducted for $78.4 \%$ of death of undetermined intent decedents and tests for amphetamines, antidepressants, benzodiazepines, cocaine, marijuana, and opiates were conducted for $39.5 \%, 48.1 \%, 49.9 \%, 48.8 \%, 32.6 \%$, and $75.1 \%$, respectively (Table 27 ). Among those who had positive results for alcohol (33.7\%), 63.5\% had BAC $\geq 0.08 \mathrm{~g} / \mathrm{dL}$. Opiates, cocaine, marijuana, and antidepressants were identified in $72.2 \%$, $23.8 \%, 17.2 \%$, and $53.7 \%$ of decedents, respectively, for whom intent of death could not be determined (Table 27).

Precipitating circumstances were known in approximately $83.7 \%$ of deaths of undetermined intent. Of those, substance abuse problems (64.0\%) and alcohol problems (26.9\%) were most common (Table 28). Although a current depressed mood was reported for only $14.2 \%$ of decedents, $39.5 \%$ had a current diagnosed mental health problem, 32.9\% were receiving mental health treatment at the time of their death, $12.8 \%$ had a history of suicide attempts, $11.3 \%$ had a history of suicidal thoughts or plans, $5.5 \%$ had disclosed intent to commit suicide, and $1.5 \%$ left a suicide note. Other common circumstances were physical health problems $(21.0 \%)$, a crisis during the preceding or upcoming 2 weeks (19.4\%), or intimate partner problems $(9.4 \%)$ (Table 28$)$. Of those with a current diagnosed mental health problem, depression/ dysthymia (59.9\%), anxiety disorder (23.5\%), and bipolar disorder (21.0\%) were the most common diagnoses (Table 29).

Among decedents for whom intent of death was undetermined, a greater percentage of males than females was reported to have alcohol problems ( $31.7 \%$ and $19.2 \%$, respectively); the percentage with other substance abuse problems was similar for males and females (64.6\% and 63.0\%) (Table 28). Mental health problems were reported for approximately half of females $(50.3 \%)$ and $32.8 \%$ of males. A higher percentage of females than of males was currently in treatment for a mental health problem $(42.1 \%$ and $27.2 \%$, respectively) or had a history of suicide attempts (16.1\% and $10.8 \%$ ) (Table 28 ).

A crisis within the previous or upcoming 2 weeks was experienced by $19.4 \%$ of decedents for whom intent of death was undetermined (Table 28). For males and females, the most common recent crises were health problems $(33.7 \%)$, other (nonalcohol) substance abuse problems (21.4\%), intimate partner problems, $(18.5 \%)$, and family relationship problems (7.6\%) (Table 30). 


\section{Unintentional Firearm Deaths}

\section{Sex, Race/Ethnicity, and Age Group}

The 17 NVDRS states included in this report collected data concerning 125 incidents involving 125 unintentional firearm deaths in 2013 (Table 31). Fifty-five (44.0\%) of these unintentional fatal firearm injuries were self-inflicted and 36 (29.0\%) were known to be inflicted by another person; for the remaining 34 (27.0\%), it was unknown who inflicted the injury (data not shown). Males accounted for $85.6 \%$ of decedents. The majority (78.4\%) were non-Hispanic whites, followed by nonHispanic blacks (12.8\%). Persons aged 15-29 years accounted for $40.8 \%$ of all unintentional firearm deaths (Table 31 ).

\section{Firearm Type, Seasonality, and Location of Injury}

Handguns were involved in $46.4 \%$ of unintentional firearm deaths, shotguns in $16.0 \%$, and rifles in $12.0 \%$. The majority of unintentional firearm deaths occurred in March, April, October, November, and December (10.4\% each month), while the fewest occurred in June (4.8\%) (Table 31). Of all unintentional firearm deaths, $69.6 \%$ occurred in a house or apartment, followed by natural areas (10.4\%) (Table 31).

\section{Context of the Injury and Associated Circumstances}

The context of the injury or associated circumstances were known for $77.6 \%$ of unintentional firearm deaths (Table 32). Overall, the most common context of injury was playing with a gun $(28.9 \%)$, followed by hunting (13.4\%) and showing a gun to others $(8.2 \%)$. The most common associated circumstance was unintentionally pulling the trigger $(20.6 \%)$, followed by thinking the gun was unloaded $(14.4 \%)$ and thinking the magazine was disengaged (8.2\%) (Table 32).

\section{Discussion}

Violent deaths occur among males and females of all ages, races, and ethnicities. NVDRS data can help identify populations particularly affected by violence. The system not only provides details on specific manners of violent deaths, but also identifies common factors for multiple types of violence. These details can increase knowledge about the circumstances associated with violence and can help public health authorities develop datainformed, effective approaches to violence prevention.

In participating states, updating to a web-based platform has simplified system operation and management, improved timeliness of data entry and reporting, and enhanced flexibility to adapt quickly to changing information needs in violence surveillance (8). Changes to the system have also improved its capacity for future expansion to additional states (8).

NVDRS data continue to illustrate that relationship problems, specifically intimate partner problems, frequently precede suicides and homicides. These findings underscore the importance of youth violence prevention programs that help improve communication skills, individual coping skills (11), and nonviolent conflict resolution skills such as impulse control, empathy, anger management, and problem solving (12-15). For example Safe Dates, which focuses on reducing dating violence among adolescents by enhancing awareness about abusive relationships, changing norms, and teaching skills to develop healthy relationships, has been reported to reduce long-term physical and sexual dating violence (16) and other types of youth violence (17). Other school-based, familyfocused, or community-based prevention programs also have been reported to reduce youth violence $(18,19)$.

Alcohol use also frequently precedes suicidal and interpersonal violent behavior $(4,7,11,20-23)$. NVDRS data indicate that alcohol was the most commonly identified substance in decedents who underwent toxicology testing; in 2013 over two-thirds of decedents with positive results for alcohol had $\mathrm{BAC} \geq 0.08 \mathrm{~g} / \mathrm{dL}$ (i.e., over the legal limit in all states). These findings suggest that comprehensive violence prevention efforts can benefit from strategies that address alcohol and other substance abuse.

Among other variables, NVDRS collects information about circumstances associated with violence. For example, analysis of NVDRS data on precipitating circumstances indicates that when homicides involve females, almost half are related to intimate partner violence. The U.S. Department of Health and Human Services recommends that women's preventive health care include screening and counseling for interpersonal and domestic violence (24). It is important that screening and counseling about abuse be done in a culturally sensitive and supportive way to address concerns about health and safety (25). An intervention with multiple counseling sessions to assess the risk for danger, discuss prevention options, develop a safety plan, and share appropriate community resources has been reported to reduce recurrence of partner violence among pregnant women (26).

At the state level, NVDRS data have been instrumental in planning, implementing, and evaluating public health policies and practices regarding violent deaths. For example, Utah Violent Death Reporting System (VDRS) data indicated that in $44.0 \%$ of intimate partner violence-related incidents, children and adolescents aged $<18$ years were living in the home. The state's Violence and Injury Prevention Program and multidisciplinary Domestic Violence Fatality Review 
Committee used these data to help children of domestic violence-related homicide victims. The data-informed policy change allows the Department of Children and Family Services to help these children receive an assessment and get access to interventions such as mental health care (27).

Current diagnosed mental health problems were a common precipitating circumstance for suicides. Depression/dysthymia was the most common diagnosis, followed by anxiety disorder and bipolar disorder. However, only one-third of suicide decedents were receiving mental health treatment, which suggests the need for strategies to enhance access to care; reduce stigma for those seeking help; and enhance social connections and support, particularly during times of crisis (11).

Other studies have indicated that on average, as many as $45.0 \%$ of persons who die by suicide had visited their primary care physician within 1 month of their death (28) and as many as $67.0 \%$ of persons who attempt suicide receive medical attention as a result of their attempt (29). Such findings suggest opportunities for suicide prevention. Primary care providers have the potential to prevent suicides, connect patients to specialty care, and collaborate or formally partner with behavioral health care providers $(30,31)$.

Colorado VDRS data on suicide among middle-aged men were used by the Colorado Department of Public Health and their partners to develop ManTherapy, a web-based suicide prevention initiative to engage and help connect men with appropriate resources $(32,33)$. The initiative was driven by continued observation that men of working age (aged 25-64 years) comprise the population with the highest rate of suicide in Colorado. Some circumstances associated with suicide among working-aged men differed considerably from those associated with women (K Bol, MSPH, Colorado Department of Public Health and Environment, personal communication, March 2016,33). Among suicides in Colorado from 2009 to 2013, $42.0 \%$ of men and $64.0 \%$ of women were noted to have a current diagnosed mental health problem during investigation; have ever been treated for a mental health problem $(39.0 \%$ and $58.0 \%$, respectively); have a diagnosis of depression (31.0\% and $49.0 \%)$; or be receiving mental health treatment at the time of the suicide $(30.0 \%$ and $51.0 \%)$. These findings suggest reticence among men to seek mental health care or to discuss a mental health diagnosis or treatment with those closest them (e.g., family members and friends). Initial web analytics indicate that the program had over 285,000 unique visits between mid-2012 and early 2014 , with $83.0 \%$ of survey respondents reporting they would recommend the site to a friend in need and $73.0 \%$ reporting they were directed to appropriate resources (32).
Suicide data from the Rhode Island VDRS (27) identified working-age males as being at increased risk for suicide and suicide attempts. Mental health and substance abuse problems, interpersonal problems, and employment-related stressors were identified as common circumstances preceding suicide in this population. As a result, a symposium with the two largest employers in the state was conducted to present these findings and increase awareness of factors precipitating suicide among working-age adults. Strategies were provided for integrating suicide prevention into worksites (27). One large employee assistance program in the state integrated suicide prevention into its mission statement and began providing training to their clinical staff and clients in early identification and referral of at-risk employees.

At the national level, NVDRS data are relevant to two national prevention initiatives, the National Strategy for Suicide Prevention (NSSP) and Healthy People $2020(34,35)$. The NSSP is a comprehensive national agenda for suicide prevention (34). Healthy People 2020 includes specific objectives for reducing the number of suicides, homicides, and firearm-related deaths and increasing the number of states that link data on violent deaths from death certificates, law enforcement reports, and coroner/medical examiner reports at state and local levels (35). Unlike other sources of data, NVDRS allows changing patterns in circumstances and risk profiles to be examined, which can affect how the rates are interpreted, help guide prevention activities, and monitor progress toward objectives.

In addition to providing more detail than other surveillance systems regarding the circumstances of violent deaths, NVDRS collects more complete information than other data sources on manners of death such as legal intervention deaths (36) and unintentional firearm deaths (37). In light of current calls for better data on legal intervention deaths in particular $(38,39)$, continued expansion of the NVDRS is critical to understanding the national picture of these deaths. The findings from 17 states in 2013 provide preliminary evidence of racial disparities in rates of legal intervention deaths, but further analyses are needed.

\section{Limitations}

The findings provided in this report are subject to at least eight limitations. First, NVDRS data are available from a limited number of states and therefore are not nationally representative. Second, the availability, completeness, and timeliness of data are dependent on partnerships among state VDRS and state health departments, vital statistics registrars' offices, coroners/ medical examiners, and law enforcement personnel. Data 
sharing and communication among partners are particularly challenging when states have independent county coroner systems rather than a centralized coroner/medical examiner system, a large number of law enforcement jurisdictions, or both. NVDRS incident data might be limited or incomplete for areas in which these data-sharing relations are not fully developed. Third, toxicology data are not collected consistently across all states or for all alcohol and drug categories. Toxicology testing is not conducted for all decedents, so the percentage of those with positive results for specific substances might be affected by selective testing patterns in coroner/medical examiner offices $(40)$. Fourth, abstractors are limited to the data included in the investigative reports they receive. Reports might not fully reflect all information known about an incident, particularly for homicides and legal intervention deaths, when data are less readily available until after a full investigation and adjudication are completed. Fifth, case definitions present challenges when a single death is classified differently in different documents (e.g., unintentional in a law enforcement report, homicide in a coroner/medical examiner report, and undetermined on the death certificate). NVDRS abstractors reconcile these discrepancies using standard NVDRS case definitions and select a single manner of death on the basis of all source documents; the manner of death assigned must be consistent with the manner of death noted in at least one source document. Sixth, variations in coding might occur depending on the abstractor's level of experience. For this reason, CDC provides abstractor training and states conduct blinded reabstraction of cases to test consistency and identify training needs. Seventh, medical and mental health information (e.g., type of condition and whether the decedent was currently receiving treatment) are not often captured directly from medical records but from coroner/medical examiner reports and the decedent's family members and friends. Therefore, the completeness and accuracy of this information are limited by the knowledge of the informant. Finally, protective factor data (i.e., characteristics or circumstances that reduce the risk for violent death) are not collected by NVDRS because of the nature of death certificates, coroner/medical examiner reports, and law enforcement reports, which typically contain only circumstances associated with risk factors.

\section{Conclusion}

Public health surveillance is the foundation for public health practice. Surveillance is essential to monitoring the prevalence and incidence of violence-related fatal injuries, defining priorities, and directing programmatic and violence prevention activities (41). Development and expansion of NVDRS are crucial to public health efforts at the federal, state, and local levels to reduce violence and the personal, familial, and societal consequences and costs. Further efforts are needed to increase the number of states participating in NVDRS to include all 50 states, U.S. territories, and the District of Columbia, with the ultimate goal of full national representation.

\section{Acknowledgments}

Contributors to this report included participating state Violent Death Reporting Systems; participating state agencies, including state health departments, vital registrars' offices, coroners'/medical examiners' offices, crime laboratories, and local and state law enforcement agencies; partner organizations, including the Safe States Alliance (formerly STIPDA), National Violence Prevention Network, National Association for Public Health Statistics and Information Systems, Council of State and Territorial Epidemiologists, and Association of State and Territorial Health Officials; federal agencies, including the U.S. Department of Justice (Bureau of Justice Statistics and the Federal Bureau of Investigation) and U.S. Department of the Treasury (Bureau of Alcohol, Tobacco, and Firearms); the International Association of Chiefs of Police; other stakeholders, researchers, and foundations, including Harvard University School of Public Health and the Joyce Foundation; and the National Institute for Occupational Safety and Health and National Center for Health Statistics, CDC.

\section{References}

1. CDC. Web-based Injury Statistics Query and Reporting System (WISQARS). Atlanta, GA: CDC; 2013. http://www.cdc.gov/injury/ wisqars/index.html

2. Paulozzi LJ, Mercy J, Frazier L Jr, Annest JL. CDC's National Violent Death Reporting System: background and methodology. Inj Prev 2004;10:47-52. http://dx.doi.org/10.1136/ip.2003.003434

3. Institute of Medicine. Reducing the burden of injury: advancing prevention and treatment. Washington DC: National Academies Press; 1999. http://www.nap.edu/read/6321

4. Karch DL, Lubell KM, Friday J, Patel N, Williams DD. Surveillance for violent deaths-National Violent Death Reporting System, 16 states, 2005. MMWR Surveill Summ 2008;57(No. SS-3).

5. US Census Bureau. QuickFacts: United States. http://www.census.gov/ quickfacts/

6. World Health Organization. International classification of diseases, tenth revision. Geneva, Switzerland: World Health Organization; 2007. http:// www.who.int/classifications/icd/en/

7. Parks SE, Johnson LL, McDaniel DD, Gladden M. Surveillance for violent deaths-National Violent Death Reporting System, 16 states, 2010. MMWR Surveill Summ 2014;63(No. SS-1).

8. Blair JM, Fowler KA, Jack SP, Crosby AE. The National Violent Death Reporting System: overview and future directions. Inj Prev 2016;22(Suppl 1):i6-11. http://dx.doi.org/10.1136/injuryprev-2015-041819

9. Murphy SL, Xu JQ, Kochanek KD; National Center for Health Statistics Division of Vital Statistics. Deaths: final data for 2010. National Vital Statistics Reports volume 61, number 4. Hyattsville, MD: CDC; May 8, 2013. http://www.cdc.gov/nchs/data/nvsr/nvsr61/nvsr61_04.pdf

10. National Center for Health Statistics. US census populations with bridged race categories. Hyattsville, MD: CDC; 2015. http://www.cdc. gov/nchs/nvss/bridged_race.htm 
11. Karch DL, Logan J, McDaniel D, Parks S, Patel N. Surveillance for violent deaths - National Violent Death Reporting System, 16 states, 2009. MMWR Surveill Summ 2012;61(No. SS-6).

12. Kotulak R. Inside the brain: revolutionary discoveries of how the mind works. Kansas City, MO: Andrews McMeel Publishing; 1997.

13. Karr-Morse R, Wiley MS. Ghosts from the nursery: tracing the roots of violence. New York, NY: Atlantic Monthly Press; 1997.

14. National Scientific Council on the Developing Child. Persistent fear and anxiety can affect young children's learning and development: working paper no. 9; 2010. http://developingchild.harvard.edu/

15. Gunnar MR. Quality of early care and buffering of neuroendocrine stress reactions: potential effects on the developing human brain. Prev Med 1998;27:208-11. http://dx.doi.org/10.1006/pmed.1998.0276

16. Foshee VA, Bauman KE, Ennett ST, Linder GF, Benefield T, Suchindran C. Assessing the long-term effects of the Safe Dates program and a booster in preventing and reducing adolescent dating violence victimization and perpetration. Am J Public Health 2004;94:619-24. http://dx.doi.org/10.2105/AJPH.94.4.619

17. Foshee VA, Reyes LM, Agnew-Brune CB, et al. The effects of the evidence-based Safe Dates dating abuse prevention program on other youth violence outcomes. Prev Sci 2014;15:907-16. http://dx.doi. org/10.1007/s11121-014-0472-4

18. Hahn R, Fuqua-Whitley D, Wethington H, et al.; Task Force on Community Preventive Services. The effectiveness of universal schoolbased programs for the prevention of violent and aggressive behavior: a report on recommendations of the Task Force on Community Preventive Services. MMWR Recomm Rep 2007;56(No. RR-7).

19. David-Ferdon C, Simon TR. Preventing youth violence: opportunities for action. Atlanta, GA: National Center for Injury Prevention and Control, CDC; 2014.

20. Karch DL, Logan J, Patel N. Surveillance for violent deaths-National Violent Death Reporting System, 16 states, 2008. MMWR Surveill Summ 2011;60(No. SS-10).

21. Karch DL, Dahlberg LL, Patel N. Surveillance for violent deathsNational Violent Death Reporting System, 16 states, 2007. MMWR Surveill Summ 2010;59(No. SS-4).

22. Karch DL, Dahlberg LL, Patel N, et al. Surveillance for violent deathsnational violent death reporting system, 16 states, 2006. MMWR Surveill Summ 2009;58(No. SS-1).

23. Darke S, Duflou J, Torok M. Drugs and violent death: comparative toxicology of homicide and non-substance toxicity suicide victims. Addiction 2009;104:1000-5. http://dx.doi.org/10.1111/j.1360-0443.2009.02565.x

24. Health Resources and Services Administration. Women's preventive services guidelines. Washington, DC: US Department of Health and Human Services; 2011. http://www.hrsa.gov/womensguidelines/index.html

25. Institute of Medicine. Clinical preventive services for women: closing the gaps. Washington DC: Institute of Medicine; 2011. http:// nationalacademies.org/hmd/Reports/2011/Clinical-Preventive-Servicesfor-Women-Closing-the-Gaps/Recommendations.aspx

26. Kiely M, El-Mohandes AA, El-Khorazaty MN, Blake SM, Gantz MG. An integrated intervention to reduce intimate partner violence in pregnancy: a randomized controlled trial. Obstet Gynecol 2010;115:27383. http://dx.doi.org/10.1097/AOG.0b013e3181 cbd482
27. Safe States Alliance. NVDRS: stories from the frontlines of violent death surveillance; 2015. http://c.ymcdn.com/sites/www.safestates.org/ resource/resmgr/NVDRS/NVDRS_Stories___2015.pdf

28. Luoma JB, Martin CE, Pearson JL. Contact with mental health and primary care providers before suicide: a review of the evidence. Am J Psychiatry 2002;159:909-16. http://dx.doi.org/10.1176/appi.ajp.159.6.909

29. Lipari R, Piscopo K, Kroutil LA, Kilmer Miller G; Substance Abuse and Mental Health Services Administration. Suicidal thoughts and behavior among adults: results from the 2014 National Survey on Drug Use and Health; September 2015. http://www.samhsa.gov/data/sites/default/ files/NSDUH-FRR2-2014/NSDUH-FRR2-2014.pdf

30. Reed J. Primary care: a crucial setting for suicide prevention. http:// www.integration.samhsa.gov/about-us/esolutions-newsletter/ suicide-prevention-in-primary-care

31. Niederkrotenthaler T, Logan J, Karch DL, Crosby AE. Characteristics of U.S. suicide decedents in 2005-2010 who had received mental health treatment. Psychiatr Serv 2014;65:387-90. http://dx.doi.org/10.1176/ appi.ps. 201300124

32. Spencer-Thomas S, Hindman J, Conrad J. ManTherapyTM: an innovative approach to suicide prevention for working aged men [White paper]; 2012. http://mantherapy.org/pdf/ManTherapy.pdf

33. Colorado Department of Public Health and Environment. Office of Suicide Prevention annual report: suicide prevention in Colorado 2014-2015; 2015. https://www.colorado.gov/pacific/sites/default/files/ PW_ISVP_OSP-2014-2015-Legislative-Report.pdf

34. Office of the Surgeon General; National Alliance for Suicide Prevention. 2012 national strategy for suicide prevention: goals and objectives for action. Washington, DC: US Department of Health and Human Services; 2012.

35. US Department of Health and Human Services. Healthy People 2020. Washington, DC: CDC; 2013. https://www.healthypeople.gov/2020/ topicsobjectives2020/default.aspx

36. Barber C, Azrael D, Cohen A, et al. Homicides by police: comparing counts from the National Violent Death Reporting System, vital statistics, and supplementary homicide reports. Am J Public Health 2016;106:922-7. http://dx.doi.org/10.2105/AJPH.2016.303074

37. Barber C, Hemenway D. Too many or too few unintentional firearm deaths in official U.S. mortality data? Accid Anal Prev 2011;43:724-31. http://dx.doi.org/10.1016/j.aap.2010.10.018

38. Office of the Attorney General. Attorney General Holder urges improved data reporting on both shootings of police officers and use of force by the police. Washington, DC: U.S. Department of Justice; 2015. https:// www.justice.gov/opa/pr/attorney-general-holder-urges-improved-datareporting-both-shootings-police-officers-and-use

39. Kindy K. FBI to sharply expand system for tracking fatal police shootings. Washington Post. December 8, 2015. https://www.washingtonpost.com/ national/fbi-to-sharply-expand-system-for-tracking-fatal-policeshootings/2015/12/08/a60fbc16-9dd4-11e5-bce4-708fe33e3288_story.html

40. Karch D, Crosby A, Simon T. Toxicology testing and results for suicide victims-13 states, 2004. MMWR Morb Mortal Wkly Rep 2006;55:1245-8.

41. Steenkamp M, Frazier L, Lipskiy N, et al. The National Violent Death Reporting System: an exciting new tool for public health surveillance. Inj Prev 2006;12(Suppl 2):ii3-5. http://dx.doi.org/10.1136/ ip. 2006.012518 
TABLE 1. Number, ${ }^{*}$ percentage, ${ }^{\dagger}$ and rate $^{\S}$ of deaths, by incident type, manner of death, method used, and location where injury occurred — National Violent Death Reporting System, 17 states, " 2013

\begin{tabular}{|c|c|c|}
\hline Characteristic & No. (\%) & Rate \\
\hline \multicolumn{3}{|l|}{ Incident type } \\
\hline Suicide, single & $12,487(66.5)$ & 13.0 \\
\hline Homicide, single & $3,836(20.4)$ & 4.0 \\
\hline Undetermined intent, single & $1,672(8.9)$ & 1.7 \\
\hline Unintentional firearm, single & $125(<1.0)$ & 0.1 \\
\hline Suicide, multiple & $17(<1.0)$ & ** \\
\hline Homicide, multiple & $166(<1.0)$ & *** \\
\hline Undetermined intent, multiple & $11(<1.0)$ & ** \\
\hline Legal intervention, ${ }^{\dagger \dagger}$ single/multiple & $220(1.2)$ & ** \\
\hline Homicide followed by suicide & $225(1.2)$ & ** \\
\hline Other combinations of deaths & $6(<1.0)$ & ** \\
\hline Total & $18,765(100)$ & 19.5 \\
\hline \multicolumn{3}{|l|}{ Manner of death } \\
\hline Suicide & $12,747(66.2)$ & 13.3 \\
\hline Homicide & $4,459(23.2)$ & 4.6 \\
\hline Undetermined intent & 1,698 (8.8) & 1.8 \\
\hline Legal intervention ${ }^{\dagger \dagger}$ & $222(1.2)$ & 0.2 \\
\hline Unintentional firearm & $125(<1.0)$ & 0.1 \\
\hline Total & $19,251(100)$ & 20.1 \\
\hline \multicolumn{3}{|l|}{ Method } \\
\hline Firearm & $9,870(51.3)$ & 10.3 \\
\hline Hanging/strangulation/suffocation & $3,310(17.2)$ & 3.4 \\
\hline Poisoning & $3,137(16.3)$ & 3.3 \\
\hline Sharp instrument & $766(4.0)$ & 0.8 \\
\hline Blunt instrument & $336(1.7)$ & 0.4 \\
\hline Fall & $282(1.5)$ & 0.3 \\
\hline $\begin{array}{l}\text { Motor vehicle (e.g., car, bus, motorcycle, } \\
\text { other transport vehicle) }\end{array}$ & $233(1.2)$ & 0.2 \\
\hline Personal weapons (e.g., hands, feet, fists) & $229(1.2)$ & 0.2 \\
\hline Drowning & $158(<1.0)$ & 0.2 \\
\hline Fire/burns & $102(<1.0)$ & 0.1 \\
\hline Intentional neglect & $18(<1.0)$ & $\S \S$ \\
\hline Other (single method) & $55(<1.0)$ & 0.1 \\
\hline Unknown & 755 (3.9) & 0.8 \\
\hline Total & $19,251(100)$ & 20.1 \\
\hline
\end{tabular}

TABLE 1. (Continued) Number, ${ }^{*}$ percentage, ${ }^{\dagger}$ and rate $^{\S}$ of deaths, by incident type, manner of death, method used, and location where injury occurred - National Violent Death Reporting System, 17 states, " 2013

\begin{tabular}{lrr}
\hline Characteristic & No. $(\%)$ & Rate \\
\hline Location & $13,359(69.4)$ & 13.9 \\
House or apartment & $1,241(6.4)$ & 1.3 \\
Street or highway & $939(4.9)$ & 1.0 \\
Motor vehicle & $730(3.8)$ & 0.8 \\
Natural area & $354(1.8)$ & 0.4 \\
Hotel/motel & $340(1.8)$ & 0.4 \\
Parking lot/public garage/public transport & $250(1.3)$ & 0.3 \\
Commercial/retail area & $233(1.2)$ & 0.2 \\
Park, playground, sports/athletic area & $221(1.1)$ & 0.2 \\
Jail/prison & $112(<1.0)$ & 0.1 \\
Bar/nightclub & $94(<1.0)$ & 0.1 \\
Railroad tracks & $65(<1.0)$ & 0.1 \\
Supervised residential facility & $63(<1.0)$ & 0.1 \\
Hospital or medical facility & $41(<1.0)$ & 0 \\
Industrial or construction area & $37(<1.0)$ & 0 \\
Abandoned house/building/warehouse & $37(<1.0)$ & 0 \\
Office building & $34(<1.0)$ & 0 \\
Preschool/school/college/school bus & $24(<1.0)$ & 0 \\
Farm & $313(1.6)$ & 0.3 \\
Other & $764(4.0)$ & 0.8 \\
Unknown & $19,251(100)$ & 20.1 \\
Total &
\end{tabular}

${ }^{*}$ No. incidents $=18,765 ;$ no. deaths $=19,251$ (19,010 victims [98.7\%], 241 suspects/victims [1.3\%]). The incident type characteristic reports number of incidents; all others report number of deaths.

† Percentages might not total $100 \%$ due to rounding.

$\S$ Per 100,000 population.

I Alaska, Colorado, Georgia, Kentucky, Maryland, Massachusetts, North Carolina, New Jersey, New Mexico, Ohio, Oklahoma, Oregon, Rhode Island, South Carolina, Utah, Virginia, and Wisconsin.

** Because the number of victims varies in incidents involving multiple deaths, numerators cannot be determined to compute rates.

${ }^{+\dagger}$ The term legal intervention does not denote the lawfulness or legality of the circumstances surrounding the death.

$\S \S$ Rate is not reported when number of deaths is $<20$. 
TABLE 2. Number* and percentage of decedents tested for alcohol and drugs and whose results were positive, ${ }^{\dagger}$ by toxicology variable — National Violent Death Reporting System, 17 states, \$2013

\begin{tabular}{|c|c|c|}
\hline & Tested & Positive \\
\hline Toxicology variable & No. (\%) & No. $(\%)$ \\
\hline BAC & $11,403(59.2)$ & $4,289(37.6)$ \\
\hline Alcohol $<0.08 \mathrm{~g} / \mathrm{dL}$ & & $1,258(29.3)$ \\
\hline Alcohol $\geq 0.08 \mathrm{~g} / \mathrm{dL}$ & & $2,910(67.8)$ \\
\hline Alcohol positive, level unknown & & $121(2.8)$ \\
\hline Amphetamines & $6,845(35.6)$ & $627(9.2)$ \\
\hline Anticonvulsants & $4,532(23.5)$ & $518(11.4)$ \\
\hline Antidepressants & $5,528(28.7)$ & $1,836(33.2)$ \\
\hline Antipsychotics & $4,688(24.4)$ & $411(8.8)$ \\
\hline Barbiturates & $5,487(28.5)$ & $134(2.4)$ \\
\hline Benzodiazepines & $6,757(35.1)$ & $1,959(29.0)$ \\
\hline Carbon monoxide & $2,522(13.1)$ & $390(15.5)$ \\
\hline Cocaine & $7,477(38.8)$ & 778 (10.4) \\
\hline Marijuana & $5,894(30.6)$ & $1,415(24.0)$ \\
\hline Muscle relaxants & $4,556(23.7)$ & $337(7.4)$ \\
\hline Opiates & $8,127(42.2)$ & $2,586(31.8)$ \\
\hline Other drugs/substances** & $3,503(18.2)$ & $3,471(99.1)$ \\
\hline
\end{tabular}

Abbreviation: $\mathrm{BAC}=$ blood alcohol concentration.

* No. decedents $=19,251$.

+ Percentage is of decedents tested for toxicology variable.

$\S$ Alaska, Colorado, Georgia, Kentucky, Maryland, Massachusetts, North Carolina, New Jersey, New Mexico, Ohio, Oklahoma, Oregon, Rhode Island, South Carolina, Utah, Virginia, and Wisconsin.

I $B A C \geq 0.08 \mathrm{~g} / \mathrm{dL}$ is over the legal limit in all states and is used as the standard for intoxication.

** Other drugs/substances indicated if any results were positive; levels for these drugs/substances are not measured.
TABLE 3. Number, ${ }^{*}$ percentage, ${ }^{\dagger}$ and rate $^{\S}$ of suicides, by method used and month in which suicide occurred - National Violent Death Reporting System, 17 states, " 2013

\begin{tabular}{|c|c|c|}
\hline Characteristic & No. $(\%)$ & Rate \\
\hline \multicolumn{3}{|l|}{ Method } \\
\hline Firearm & $6,548(51.4)$ & 6.8 \\
\hline Hanging/strangulation/suffocation & $3,118(24.5)$ & 3.2 \\
\hline Poisoning & $1,975(15.5)$ & 2.1 \\
\hline Sharp instrument & $242(1.9)$ & 0.3 \\
\hline Fall & $234(1.8)$ & 0.2 \\
\hline $\begin{array}{l}\text { Motor vehicle (e.g., car, bus, motorcycle, } \\
\text { other transport vehicle) }\end{array}$ & $175(1.4)$ & 0.2 \\
\hline Drowning & $100(<1.0)$ & 0.1 \\
\hline Fire/burns & $45(<1.0)$ & 0 \\
\hline Blunt instrument & $12(<1.0)$ & ** \\
\hline Intentional neglect & $1(<1.0)$ & ** \\
\hline Personal weapons (e.g., hands, feet, fists) & $1(<1.0)$ & $* *$ \\
\hline Other (single method) & $16(<1.0)$ & ** \\
\hline Unknown & $280(2.2)$ & 0.3 \\
\hline Total & $12,747(100)$ & 13.3 \\
\hline \multicolumn{3}{|l|}{ Month } \\
\hline January & $1,077(8.4)$ & 1.1 \\
\hline February & $970(7.6)$ & 1.0 \\
\hline March & $1,139(8.9)$ & 1.2 \\
\hline April & $1,032(8.1)$ & 1.1 \\
\hline May & $1,042(8.2)$ & 1.1 \\
\hline June & $1,065(8.4)$ & 1.1 \\
\hline July & $1,106(8.7)$ & 1.2 \\
\hline August & $1,086(8.5)$ & 1.1 \\
\hline September & $1,026(8.0)$ & 1.1 \\
\hline October & $1,069(8.4)$ & 1.1 \\
\hline November & 975 (7.6) & 1.0 \\
\hline December & $935(7.3)$ & 1.0 \\
\hline Unknown & $225(1.8)$ & 0.2 \\
\hline Total & $12,747(100)$ & 13.3 \\
\hline
\end{tabular}

* No. incidents $=12,729 ;$ no. deaths $=12,747$.

+ Percentages might not total $100 \%$ due to rounding.

$\S$ Per 100,000 population.

" Alaska, Colorado, Georgia, Kentucky, Maryland, Massachusetts, North Carolina, New Jersey, New Mexico, Ohio, Oklahoma, Oregon, Rhode Island, South Carolina, Utah, Virginia, and Wisconsin.

** Rate is not reported when number of deaths is $<20$. 
TABLE 4. Number, percentage, ${ }^{*}$ and rate ${ }^{\dagger}$ of suicides, by decedent's sex, age group, race/ethnicity, and marital status — National Violent Death Reporting System, 17 states, $\$ 2013$

\begin{tabular}{|c|c|c|c|c|c|c|}
\hline \multirow[b]{2}{*}{ Characteristic } & \multicolumn{2}{|c|}{ Male } & \multicolumn{2}{|c|}{ Female } & \multicolumn{2}{|c|}{ Total ${ }^{\Upsilon 1}$} \\
\hline & No. (\%) & Rate & No. (\%) & Rate & No. (\%) & Rate \\
\hline \multicolumn{7}{|l|}{ Age group (yrs) } \\
\hline$<10$ & $* *$ & $* *$ & $* *$ & $* *$ & $* *$ & $* *$ \\
\hline $10-14$ & $80(<1.0)$ & 2.5 & 45 (1.6) & 1.5 & $125(1.0)$ & 2.0 \\
\hline $15-19$ & $434(4.4)$ & 13.2 & $116(4.0)$ & 3.7 & $550(4.3)$ & 8.6 \\
\hline $20-24$ & $809(8.2)$ & 23.1 & $173(6.0)$ & 5.2 & $982(7.7)$ & 14.3 \\
\hline $25-29$ & 849 (8.6) & 26.1 & $188(6.6)$ & 5.9 & $1,037(8.1)$ & 16.1 \\
\hline $30-34$ & $788(8.0)$ & 24.6 & $233(8.1)$ & 7.2 & $1,021(8.0)$ & 15.9 \\
\hline $35-44$ & $1,574(15.9)$ & 25.6 & $484(16.9)$ & 7.8 & $2,058(16.1)$ & 16.6 \\
\hline $45-54$ & 1,959 (19.8) & 29.6 & 707 (24.6) & 10.3 & $2,666(20.9)$ & 19.8 \\
\hline $55-64$ & $1,665(16.9)$ & 28.7 & $558(19.4)$ & 8.9 & $2,224(17.4)$ & 18.4 \\
\hline $65-74$ & $902(9.1)$ & 25.2 & $235(8.2)$ & 5.8 & 1,137 (8.9) & 14.8 \\
\hline $75-84$ & $554(5.6)$ & 33.0 & $88(3.1)$ & 3.9 & $643(5.0)$ & 16.3 \\
\hline$\geq 85$ & $261(2.6)$ & 45.5 & $40(1.4)$ & 3.4 & $301(2.4)$ & 17.3 \\
\hline Unknown & $0(0)$ & t† & $1(<1.0)$ & t† & $1(<1.0)$ & t† \\
\hline Total & $9,876(100)$ & 21.0 & $2,869(100)$ & 5.9 & $12,747(100)$ & 13.3 \\
\hline \multicolumn{7}{|l|}{ Race/Ethnicity } \\
\hline White, non-Hispanic & $8,342(84.5)$ & 25.8 & $2,450(85.4)$ & 7.3 & $10,792(84.7)$ & 16.4 \\
\hline Black, non-Hispanic & $637(6.4)$ & 9.1 & $154(5.4)$ & 2.0 & $791(6.2)$ & 5.3 \\
\hline American Indian/Alaska Native & $167(1.7)$ & 30.2 & 44 (1.5) & 7.7 & $211(1.7)$ & 18.7 \\
\hline Asian/Pacific Islander & 159 (1.6) & 8.2 & $53(1.8)$ & 2.5 & $212(1.7)$ & 5.2 \\
\hline Hispanic $§ \S$ & $484(4.9)$ & 9.3 & $128(4.5)$ & 2.6 & $612(4.8)$ & 6.0 \\
\hline Other & $19(<1.0)$ & t† & $10(<1.0)$ & t† & $29(<1.0)$ & t† \\
\hline Unknown & $68(<1.0)$ & t† & $30(1.0)$ & †† & $100(<1.0)$ & t† \\
\hline Total & $9,876(100)$ & 21.0 & $2,869(100)$ & 5.9 & $12,747(100)$ & 13.3 \\
\hline \multicolumn{7}{|l|}{ Marital status ๆๆ } \\
\hline Married & $3,313(34.6)$ & $* * *$ & $941(34.1)$ & $* * *$ & $4,255(34.5)$ & $* * *$ \\
\hline Never married & $3,019(31.5)$ & $* * *$ & $651(23.6)$ & $* * *$ & $3,670(29.7)$ & $* * *$ \\
\hline Widowed & $519(5.4)$ & $* * *$ & $236(8.6)$ & $* * *$ & $756(6.1)$ & $* * *$ \\
\hline Divorced & $1,921(20.0)$ & $* * *$ & $743(26.9)$ & $* * *$ & $2,664(21.6)$ & $* * *$ \\
\hline Married but separated & $301(3.1)$ & $* * *$ & $79(2.9)$ & $* * *$ & $380(3.1)$ & $* * *$ \\
\hline Single, not otherwise specified & $314(3.3)$ & $* * *$ & $44(1.6)$ & $* * *$ & $358(2.9)$ & $* * *$ \\
\hline Unknown & $202(2.1)$ & $* * *$ & $64(2.3)$ & $* * *$ & $266(2.2)$ & $* * *$ \\
\hline Total & $9,589(100)$ & $* * *$ & $2,758(100)$ & $* * *$ & $12,349(100)$ & $* * *$ \\
\hline
\end{tabular}

* Percentages might not total $100 \%$ due to rounding.

† Per 100,000 population.

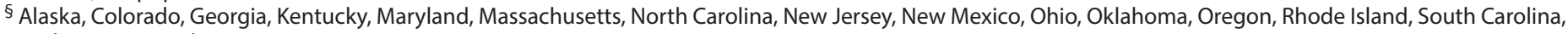
Utah, Virginia, and Wisconsin.

I Sex is unknown for two decedents; therefore, total is two greater than sum of males and females.

** Suicide is not reported for decedents aged $<10$ years, as per standard in the suicide prevention literature.

${ }^{\dagger \dagger}$ Rate is not reported when number of deaths is $<20$ or when age or race/ethnicity is other or unknown.

$\S \S$ Includes persons of any race.

११ Includes decedents aged $\geq 18$ years only.

*** Rate cannot be computed for marital status because denominator is unknown. 
TABLE 5. Number and percentage* of suicides, by decedent's sex, method used, and location where injury occurred — National Violent Death Reporting System, 17 states, ${ }^{\dagger} 2013$

\begin{tabular}{|c|c|c|c|}
\hline & Male & Female & Total $^{\S}$ \\
\hline Characteristic & No. (\%) & No. $(\%)$ & No. $(\%)$ \\
\hline \multicolumn{4}{|l|}{ Method } \\
\hline Firearm & $5,619(56.9)$ & $929(32.4)$ & $6,548(51.4)$ \\
\hline Hanging/strangulation/suffocation & $2,442(24.7)$ & $676(23.6)$ & $3,118(24.5)$ \\
\hline Poisoning & $982(9.9)$ & $993(34.6)$ & $1,975(15.5)$ \\
\hline Sharp instrument & $196(2.0)$ & $46(1.6)$ & $242(1.9)$ \\
\hline Fall & 169 (1.7) & $65(2.3)$ & $234(1.8)$ \\
\hline Motor vehicle (e.g., car, bus, motorcycle, other transport vehicle) & $133(1.3)$ & $42(1.5)$ & 175 (1.4) \\
\hline Drowning & $66(<1.0)$ & $34(1.2)$ & $100(<1.0)$ \\
\hline Fire/burns & $32(<1.0)$ & $13(0.5)$ & $45(<1.0)$ \\
\hline Blunt instrument & $5(<1.0)$ & $7(0.2)$ & $12(<1.0)$ \\
\hline Intentional neglect & $1(<1.0)$ & $0(0)$ & $1(<1.0)$ \\
\hline Personal weapons (e.g., hands, feet, fists) & $1(<1.0)$ & $0(0)$ & $1(<1.0)$ \\
\hline Other (single method) & $15(<1.0)$ & $1(<0.1)$ & $16(<1.0)$ \\
\hline Unknown & $215(2.2)$ & $63(2.2)$ & $280(2.2)$ \\
\hline Total & $9,876(100)$ & $2,869(100)$ & $12,747(100)$ \\
\hline \multicolumn{4}{|l|}{ Location } \\
\hline House or apartment & 7,297 (73.9) & $2,287(79.7)$ & $9,586(75.2)$ \\
\hline Motor vehicle & $493(5.0)$ & $96(3.3)$ & $589(4.6)$ \\
\hline Natural area & $490(5.0)$ & $99(3.5)$ & $589(4.6)$ \\
\hline Hotel/motel & $193(2.0)$ & $73(2.5)$ & $266(2.1)$ \\
\hline Street or highway & $198(2.0)$ & 45 (1.6) & $243(1.9)$ \\
\hline Park, playground, sports/athletic area & $150(1.5)$ & $26(<1.0)$ & $176(1.4)$ \\
\hline Jail/prison & $152(1.5)$ & $21(<1.0)$ & $173(1.4)$ \\
\hline Parking lot/public garage/public transport & $118(1.2)$ & $34(1.2)$ & $152(1.2)$ \\
\hline Commercial/retail area & $84(<1.0)$ & $13(<1.0)$ & $97(<1.0)$ \\
\hline Railroad tracks & $69(<1.0)$ & $17(<1.0)$ & $86(<1.0)$ \\
\hline Hospital or medical facility & $33(<1.0)$ & $12(<1.0)$ & $45(<1.0)$ \\
\hline Supervised residential facility & $24(<1.0)$ & $16(<1.0)$ & $40(<1.0)$ \\
\hline Industrial or construction area & $27(<1.0)$ & $2(<1.0)$ & $29(<1.0)$ \\
\hline Office building & $27(<1.0)$ & $2(<1.0)$ & $29(<1.0)$ \\
\hline Preschool/school/college/school bus & $20(<1.0)$ & $4(<1.0)$ & $24(<1.0)$ \\
\hline Farm & $18(<1.0)$ & $3(<1.0)$ & $21(<1.0)$ \\
\hline Abandoned house/building/warehouse & $15(<1.0)$ & $3(<1.0)$ & $18(<1.0)$ \\
\hline Bar/nightclub & $7(<1.0)$ & $0(0)$ & $7(<1.0)$ \\
\hline Other & 189 (1.9) & $39(1.4)$ & $228(1.8)$ \\
\hline Unknown & $272(2.8)$ & $77(2.7)$ & $349(2.7)$ \\
\hline Total & $9,876(100)$ & $2,869(100)$ & $12,747(100)$ \\
\hline
\end{tabular}

* Percentages might not total $100 \%$ due to rounding.

† Alaska, Colorado, Georgia, Kentucky, Maryland, Massachusetts, North Carolina, New Jersey, New Mexico, Ohio, Oklahoma, Oregon, Rhode Island, South Carolina, Utah, Virginia, and Wisconsin.

$\S$ Sex is unknown for two decedents; therefore, total is two greater than sum of males and females. 
TABLE 6. Number* and percentage of suicide decedents tested for alcohol and drugs and whose results were positive, ${ }^{\dagger}$ by toxicology variable — National Violent Death Reporting System, 17 states, $\$ 2013$

\begin{tabular}{|c|c|c|}
\hline & Tested & Positive \\
\hline Toxicology variable & No. (\%) & No. (\%) \\
\hline BACף & $7,120(55.9)$ & $2,720(38.2)$ \\
\hline Alcohol $<0.08 \mathrm{~g} / \mathrm{dL}$ & & $726(26.7)$ \\
\hline Alcohol $\geq 0.08 \mathrm{~g} / \mathrm{dL}$ & & $1,913(70.3)$ \\
\hline Alcohol positive, level unknown & & $81(3.0)$ \\
\hline Amphetamines & $4,360(34.2)$ & $316(7.2)$ \\
\hline Anticonvulsants & $2,918(22.9)$ & 348 (11.9) \\
\hline Antidepressants & $3,616(28.4)$ & $1,278(35.3)$ \\
\hline Antipsychotics & $3,032(23.8)$ & $286(9.4)$ \\
\hline Barbiturates & $3,479(27.3)$ & $106(3.0)$ \\
\hline Benzodiazepines & $4,327(33.9)$ & $1,355(31.3)$ \\
\hline Carbon monoxide & $1,647(12.9)$ & $301(18.3)$ \\
\hline Cocaine & $4,632(36.3)$ & $269(5.8)$ \\
\hline Marijuana & $3,683(28.9)$ & $612(16.6)$ \\
\hline Muscle relaxants & $2,891(22.7)$ & $231(8.0)$ \\
\hline Opiates & $4,880(38.3)$ & $1,307(26.8)$ \\
\hline Other drugs/substances** & $2,118(16.6)$ & $2,097(99.0)$ \\
\hline
\end{tabular}

Abbreviation: $\mathrm{BAC}=$ blood alcohol concentration.

* No. decedents $=12,747$.

† Percentage is of decedents tested for toxicology variable.

$\S$ Alaska, Colorado, Georgia, Kentucky, Maryland, Massachusetts, North Carolina, New Jersey, New Mexico, Ohio, Oklahoma, Oregon, Rhode Island, South Carolina, Utah, Virginia, and Wisconsin.

ๆ $B A C \geq 0.08 \mathrm{~g} / \mathrm{dL}$ is over the legal limit in all states and is used as the standard for intoxication.

** Other drugs/substances indicated if any results were positive; levels for these drugs/substances are not measured. 
TABLE 7. Number* and percentage ${ }^{\dagger}$ of suicides, by precipitating circumstance and decedent's sex — National Violent Death Reporting System, 17 states, $\$ 2013$

\begin{tabular}{|c|c|c|c|}
\hline & Male & Female & Total \\
\hline Precipitating circumstance & No. (\%) & No. (\%) & No. (\%) \\
\hline $\begin{array}{l}\text { Mental health/Substance abuse } \\
\text { Current diagnosed mental health problem } \\
\text { History of ever being treated for a mental health problem } \\
\text { Current depressed mood } \\
\text { Current mental health treatment } \\
\text { Alcohol problem } \\
\text { Other substance abuse problem (excludes alcohol) } \\
\text { Other addiction (e.g., gambling, sex) }\end{array}$ & $\begin{array}{r}3,572(41.2) \\
3,042(35.1) \\
3,264(37.7) \\
2,392(27.6) \\
1,666(19.2) \\
1,318(15.2) \\
65(<1.0)\end{array}$ & $\begin{array}{r}1,632(62.7) \\
1,441(55.4) \\
1,054(40.5) \\
1,223(47.0) \\
393(15.1) \\
514(19.7) \\
18(<1.0)\end{array}$ & $\begin{array}{r}5,204(46.2) \\
4,483(39.8) \\
4,318(38.3) \\
3,615(32.1) \\
2,059(18.3) \\
1,832(16.3) \\
83(<1.0)\end{array}$ \\
\hline $\begin{array}{l}\text { Interpersonal } \\
\text { Intimate partner problem } \\
\text { Family relationship problem } \\
\text { Other death of family member or friend within past } 5 \text { years } \\
\text { Perpetrator of interpersonal violence within past month } \\
\text { Other relationship problem (nonintimate) } \\
\text { Suicide of family member or friend within past } 5 \text { years } \\
\text { Victim of interpersonal violence within past month }\end{array}$ & $\begin{array}{r}2,700(31.2) \\
765(8.8) \\
530(6.1) \\
317(3.7) \\
238(2.7) \\
169(2.0) \\
26(<1.0)\end{array}$ & $\begin{array}{r}651(25.0) \\
319(12.3) \\
199(7.6) \\
26(1.0) \\
76(2.9) \\
90(3.5) \\
31(1.2)\end{array}$ & $\begin{array}{r}3,351(29.7) \\
1,084(9.6) \\
729(6.5) \\
343(3.0) \\
314(2.8) \\
259(2.3) \\
57(<1.0)\end{array}$ \\
\hline $\begin{array}{l}\text { Life stressor } \\
\text { Crisis within previous or upcoming } 2 \text { weeks } \\
\text { Physical health problem } \\
\text { Argument or conflict } \\
\text { Job problem } \\
\text { Financial problem } \\
\text { Recent criminal legal problem } \\
\text { Eviction or loss of home } \\
\text { Noncriminal legal problem } \\
\text { School problem } \\
\text { History of child abuse/neglect } \\
\text { Physical fight (two people, not a brawl) } \\
\text { Traumatic anniversary } \\
\text { Exposure to disaster } \\
\text { Caretaker abuse/neglect led to suicide }\end{array}$ & $\begin{array}{r}2,929(33.8) \\
1,851(21.4) \\
1,422(16.4) \\
1,182(13.6) \\
1,012(11.7) \\
899(10.4) \\
321(3.7) \\
266(3.1) \\
132(1.5) \\
55(<1.0) \\
72(<1.0) \\
54(<1.0) \\
9(<1.0) \\
1(<1.0)\end{array}$ & $\begin{array}{r}715(27.5) \\
580(22.3) \\
407(15.6) \\
215(8.3) \\
222(8.5) \\
135(5.2) \\
104(4.0) \\
70(2.7) \\
29(1.1) \\
56(2.2) \\
17(<1.0) \\
23(<1.0) \\
1(<1.0) \\
1(<1.0)\end{array}$ & $\begin{array}{r}3,644(32.3) \\
2,431(21.6) \\
1,829(16.2) \\
1,397(12.4) \\
1,234(11.0) \\
1,034(9.2) \\
425(3.8) \\
336(3.0) \\
161(1.4) \\
111(1.0) \\
89(<1.0) \\
77(<1.0) \\
10(<1.0) \\
2(<1.0)\end{array}$ \\
\hline $\begin{array}{l}\text { Crime and criminal activity } \\
\text { Precipitated by another crime } \\
\text { Crime in progress } \\
\text { Terrorist attack }\end{array}$ & $\begin{array}{r}376(4.3) \\
99(26.3) \\
0(0)\end{array}$ & $\begin{array}{r}37(1.4) \\
4(10.8) \\
0(0)\end{array}$ & $\begin{array}{r}413(3.7) \\
103(24.9) \\
0(0)\end{array}$ \\
\hline $\begin{array}{l}\text { Suicide event } \\
\text { Left a suicide note } \\
\text { History of suicidal thoughts or plan } \\
\text { History of suicide attempt }\end{array}$ & $\begin{array}{l}2,858(33.0) \\
2,699(31.1) \\
1,365(15.8)\end{array}$ & $\begin{array}{r}1,059(40.7) \\
956(36.7) \\
854(32.8)\end{array}$ & $\begin{array}{l}3,917(34.8) \\
3,655(32.4) \\
2,219(19.7)\end{array}$ \\
\hline $\begin{array}{l}\text { Suicide disclosure } \\
\text { Disclosed suicide intent }\end{array}$ & $2,238(25.8)$ & $661(25.4)$ & $2,899(25.7)$ \\
\hline $\begin{array}{l}\text { Disclosed intent to whom** } \\
\text { Previous or current intimate partner } \\
\text { Other family member } \\
\text { Friend/colleague } \\
\text { Health care worker } \\
\text { Neighbor } \\
\text { Other person } \\
\text { Unknown }\end{array}$ & $\begin{array}{r}878(39.2) \\
643(28.7) \\
253(11.3) \\
92(4.1) \\
35(1.6) \\
160(7.1) \\
177(7.9)\end{array}$ & $\begin{array}{r}214(32.4) \\
220(33.3) \\
97(14.7) \\
37(5.6) \\
7(1.1) \\
32(4.8) \\
54(8.2)\end{array}$ & $\begin{array}{r}1,092(37.7) \\
863(29.8) \\
350(12.1) \\
129(4.4) \\
42(1.4) \\
192(6.6) \\
231(8.0)\end{array}$ \\
\hline Total suicides with precipitating circumstances & $8,665(100)$ & $2,603(100)$ & $11,268(100)$ \\
\hline
\end{tabular}

* Includes suicides with one or more precipitating circumstances. Circumstances are unknown for 1,479 suicides (1,211 males, 266 females; sex is unknown for two suicides). Numbers do not equal the sums of the columns because more than one circumstance could have been present per decedent.

† Denominator includes only those suicides with one or more precipitating circumstances. Sums of percentages in columns exceed $100 \%$ because a suicide could have had more than one precipitating circumstance.

$\S$ Alaska, Colorado, Georgia, Kentucky, Maryland, Massachusetts, North Carolina, New Jersey, New Mexico, Ohio, Oklahoma, Oregon, Rhode Island, South Carolina, Utah, Virginia, and Wisconsin.

I Denominator includes only those decedents involved in an incident that was precipitated by another crime.

** Denominator is decedents who disclosed intent. 
TABLE 8. Number* and percentage ${ }^{\dagger}$ of suicide decedents with a current diagnosed mental health problem, by diagnosis — National Violent Death Reporting System, 17 states, $\$ 2013$

\begin{tabular}{|c|c|c|c|}
\hline & Male & Female & Total \\
\hline Diagnosed mental health problem & No. (\%) & No. (\%) & No. (\%) \\
\hline Depression/dysthymia & $2,553(71.5)$ & $1,238(75.9)$ & $3,791(72.8)$ \\
\hline Anxiety disorder & $507(14.2)$ & $295(18.1)$ & $802(15.4)$ \\
\hline Bipolar disorder & $441(12.3)$ & $276(16.9)$ & $717(13.8)$ \\
\hline Schizophrenia & $191(5.3)$ & $63(3.9)$ & 254 (4.9) \\
\hline PTSD & $175(4.9)$ & $38(2.3)$ & $213(4.1)$ \\
\hline ADD/ADHD & $103(2.9)$ & $16(1.0)$ & $119(2.3)$ \\
\hline OCD & $23(<1.0)$ & $7(<1.0)$ & $30(<1.0)$ \\
\hline Eating disorder & $1(<1.0)$ & $16(1.0)$ & $17(<1.0)$ \\
\hline Other & $291(8.1)$ & $132(8.1)$ & $423(8.1)$ \\
\hline Unknown & $380(10.6)$ & $151(9.3)$ & $531(10.2)$ \\
\hline Total decedents with a diagnosed mental health problem & $3,572(100)$ & $1,632(100)$ & $5,204(100)$ \\
\hline
\end{tabular}

Abbreviations: $\mathrm{ADD} / \mathrm{ADHD}=$ attention deficit disorder/attention deficit hyperactivity disorder; $\mathrm{OCD}=$ obsessive-compulsive disorder; $\mathrm{PTSD}=$ posttraumatic stress disorder. * Includes decedents with one or more diagnosed mental health problems. Numbers do not equal the sums of the columns because decedents could have had more than one diagnosis.

† Denominator includes only those decedents with one or more diagnosed mental health problems. Sums of percentages in columns exceed $100 \%$ because decedents could have had more than one diagnosis.

$\S$ Alaska, Colorado, Georgia, Kentucky, Maryland, Massachusetts, North Carolina, New Jersey, New Mexico, Ohio, Oklahoma, Oregon, Rhode Island, South Carolina, Utah, Virginia, and Wisconsin.

TABLE 9. Number* and percentage ${ }^{\dagger}$ of suicide decedents who experienced a recent crisis, by type of crisis and decedent's sex — National Violent Death Reporting System, 17 states, ${ }^{\S} 2013$

\begin{tabular}{|c|c|c|c|}
\hline & Male & Female & Total \\
\hline Type of crisis & No. (\%) & No. (\%) & No. (\%) \\
\hline Intimate partner problem & 1,285 (43.9) & $277(38.7)$ & $1,562(42.9)$ \\
\hline Recent criminal legal problem & $447(15.3)$ & $52(7.3)$ & 499 (13.7) \\
\hline Physical health problem & $373(12.7)$ & $89(12.4)$ & $462(12.7)$ \\
\hline Family relationship problem & $243(8.3)$ & $101(14.1)$ & 344 (9.4) \\
\hline Job problem & $213(7.3)$ & $41(5.7)$ & $254(7.0)$ \\
\hline Eviction or loss of home & $123(4.2)$ & $38(5.3)$ & $161(4.4)$ \\
\hline Financial problem & $113(3.9)$ & $30(4.2)$ & $143(3.9)$ \\
\hline Current diagnosed mental health problem & $71(2.4)$ & $45(6.3)$ & $116(3.2)$ \\
\hline Alcohol problem & $86(2.9)$ & $21(2.9)$ & $107(2.9)$ \\
\hline Other death of friend or family member & $70(2.4)$ & $30(4.2)$ & $100(2.7)$ \\
\hline Other substance abuse problem & $69(2.4)$ & $17(2.4)$ & $86(2.4)$ \\
\hline Other relationship problem & $71(2.4)$ & $15(2.1)$ & $86(2.4)$ \\
\hline Noncriminal legal problem & $61(2.1)$ & $17(2.4)$ & $78(2.1)$ \\
\hline School problem & $39(1.3)$ & $7(1.0)$ & $46(1.3)$ \\
\hline Suicide of friend or family member & $18(<1.0)$ & $10(1.4)$ & $28(<1.0)$ \\
\hline Other addiction (e.g., gambling, sex) & $5(<1.0)$ & $0(0)$ & $5(<1.0)$ \\
\hline Disaster exposure & $1(<1.0)$ & $0(0)$ & $1(<1.0)$ \\
\hline Other crisis & $402(13.7)$ & $100(14.0)$ & $502(13.8)$ \\
\hline Total decedents who experienced a recent crisis & $2,929(100)$ & $715(100)$ & $3,644(100)$ \\
\hline
\end{tabular}

* Includes decedents who experienced one or more crises within the previous or upcoming 2 weeks. Numbers do not equal the sums of the columns because more than one crisis could have been experienced per decedent.

${ }^{\dagger}$ Denominator includes only those decedents who experienced one or more crises within the previous or upcoming 2 weeks. Sums of percentages in columns exceed $100 \%$ because a decedent could have experienced more than one crisis.

$\S$ Alaska, Colorado, Georgia, Kentucky, Maryland, Massachusetts, North Carolina, New Jersey, New Mexico, Ohio, Oklahoma, Oregon, Rhode Island, South Carolina, Utah, Virginia, and Wisconsin. 
TABLE 10. Number,* ${ }^{*}$ percentage, ${ }^{\dagger}$ and rate $^{\S}$ of homicides/legal intervention" deaths, by method used and month in which death occurred - National Violent Death Reporting System, 17 states, ${ }^{* *} 2013$

\begin{tabular}{|c|c|c|}
\hline Characteristic & No. (\%) & Rate \\
\hline \multicolumn{3}{|l|}{ Method } \\
\hline Firearm & $3,119(66.6)$ & 3.2 \\
\hline Sharp instrument & $519(11.1)$ & 0.5 \\
\hline Blunt instrument & $263(5.6)$ & 0.3 \\
\hline Personal weapons (e.g., hands, feet, fists) & $221(4.7)$ & 0.2 \\
\hline Hanging/strangulation/suffocation & $156(3.3)$ & 0.2 \\
\hline $\begin{array}{l}\text { Motor vehicle (e.g., car, bus, motorcycle, } \\
\text { other transport vehicle) }\end{array}$ & $30(<1.0)$ & 0 \\
\hline Fire/burns & $26(<1.0)$ & 0 \\
\hline Poisoning & $17(<1.0)$ & t† \\
\hline Intentional neglect & $15(<1.0)$ & tt \\
\hline Fall & $9(<1.0)$ & t+ \\
\hline Drowning & $5(<1.0)$ & t+ \\
\hline Other (single method) & $25(<1.0)$ & 0 \\
\hline Unknown & $276(5.9)$ & 0.3 \\
\hline Total & $4,681(100)$ & 4.9 \\
\hline \multicolumn{3}{|l|}{ Month } \\
\hline January & $402(8.6)$ & 0.4 \\
\hline February & $310(6.6)$ & 0.3 \\
\hline March & $321(6.9)$ & 0.3 \\
\hline April & $368(7.9)$ & 0.4 \\
\hline May & $396(8.5)$ & 0.4 \\
\hline June & $397(8.5)$ & 0.4 \\
\hline July & $439(9.4)$ & 0.5 \\
\hline August & $392(8.4)$ & 0.4 \\
\hline September & $359(7.7)$ & 0.4 \\
\hline October & $382(8.2)$ & 0.4 \\
\hline November & $423(9.0)$ & 0.4 \\
\hline December & $417(8.9)$ & 0.4 \\
\hline Unknown & 75 (1.6) & 0.1 \\
\hline Total & $4,681(100)$ & 4.9 \\
\hline
\end{tabular}

$*$ No. incidents $=4,448$; no. deaths $=4,681$.

† Percentages might not total $100 \%$ due to rounding.

$\S$ Per 100,000 population.

I The term legal intervention does not denote the lawfulness or legality of the circumstances surrounding the death.

** Alaska, Colorado, Georgia, Kentucky, Maryland, Massachusetts, North Carolina, New Jersey, New Mexico, Ohio, Oklahoma, Oregon, Rhode Island, South Carolina, Utah, Virginia, and Wisconsin.

${ }^{\dagger \dagger}$ Rate is not reported when number of deaths is $<20$.
TABLE 11. Number* and percentage ${ }^{\dagger}$ of homicides/legal intervention $\S$ deaths, by decedent's marital status and victim-suspect ${ }^{\natural}$ relationship — National Violent Death Reporting System, 17 states, ${ }^{* *} 2013$

\begin{tabular}{lr}
\hline Characteristic & No. (\%) \\
\hline Marital status ${ }^{\dagger \dagger}$ & \\
Never married & $2,306(55.5)$ \\
Married & $829(20.0)$ \\
Divorced & $544(13.1)$ \\
Single, not otherwise specified & $280(6.7)$ \\
Widowed & $139(3.3)$ \\
Married but separated & $57(1.4)$ \\
Total & $4,155(100)$ \\
Relationship & \\
Acquaintance or friend & $563(22.6)$ \\
Spouse/intimate partner (current or former) & $523(21.0)$ \\
Stranger & $301(12.1)$ \\
Victim injured by a law enforcement officer & $211(8.5)$ \\
Other relative & $160(6.4)$ \\
Child & $145(5.8)$ \\
Parent & $110(4.4)$ \\
Other intimate partner involvement ${ }^{\S \S}$ & $60(2.4)$ \\
Rival gang member & $32(1.3)$ \\
Victim was law enforcement officer injured in the & $8(<1.0)$ \\
line of duty & \\
Other person known to victim & $376(15.1)$ \\
Total & $2,489(100)$ \\
\hline
\end{tabular}

${ }^{*}$ No. deaths $=4,681$. Marital status is unknown for 132 decedents; victimsuspect relationship is unknown for 2,192 decedents.

† Percentages might not total $100 \%$ due to rounding.

$\S$ The term legal intervention does not denote the lawfulness or legality of the circumstances surrounding the death.

" A victim is a person whose death resulted from a violence-related injury; a suspect is a person believed to have inflicted a fatal injury.

** Alaska, Colorado, Georgia, Kentucky, Maryland, Massachusetts, North Carolina, New Jersey, New Mexico, Ohio, Oklahoma, Oregon, Rhode Island, South Carolina, Utah, Virginia, and Wisconsin.

t+ Includes decedents aged $\geq 18$ years only.

$\S \S$ Death was due to intimate partner-related violence but not between the intimate partners (e.g., child killed by mother's boyfriend). 
TABLE 12. Number, percentage,* and rate ${ }^{\dagger}$ of homicides/legal intervention ${ }^{\S}$ deaths, by decedent's sex, age group, and race/ethnicity — National Violent Death Reporting System, 17 states, " 2013

\begin{tabular}{|c|c|c|c|c|c|c|}
\hline \multirow[b]{2}{*}{ Characteristic } & \multicolumn{2}{|c|}{ Male } & \multicolumn{2}{|c|}{ Female } & \multicolumn{2}{|c|}{ Total } \\
\hline & No. (\%) & Rate & No. (\%) & Rate & No. (\%) & Rate \\
\hline \multicolumn{7}{|l|}{ Age group (yrs) } \\
\hline$<1$ & $56(1.5)$ & 9.3 & $34(3.2)$ & 5.9 & 90 (1.9) & 7.6 \\
\hline $1-4$ & $55(1.5)$ & 2.2 & $46(4.4)$ & 2.0 & $101(2.2)$ & 2.1 \\
\hline $5-9$ & $25(<1.0)$ & 0.8 & $15(1.4)$ & ** & $40(<1.0)$ & 0.6 \\
\hline $10-14$ & $31(<1.0)$ & 1.0 & $13(1.2)$ & $* *$ & $44(<1.0)$ & 0.7 \\
\hline $15-19$ & $311(8.6)$ & 9.5 & $46(4.4)$ & 1.5 & $357(7.6)$ & 5.6 \\
\hline $20-24$ & $716(19.7)$ & 20.4 & $113(10.7)$ & 3.4 & $829(17.7)$ & 12.1 \\
\hline $25-29$ & $550(15.2)$ & 16.9 & $104(9.9)$ & 3.3 & $654(14.0)$ & 10.1 \\
\hline $30-34$ & $446(12.3)$ & 13.9 & $112(10.6)$ & 3.5 & $558(11.9)$ & 8.7 \\
\hline $35-44$ & $573(15.8)$ & 9.3 & $182(17.3)$ & 2.9 & $755(16.1)$ & 6.1 \\
\hline $45-54$ & $448(12.3)$ & 6.8 & 167 (15.9) & 2.4 & $615(13.1)$ & 4.6 \\
\hline $55-64$ & $260(7.2)$ & 4.5 & $113(10.7)$ & 1.8 & $373(8.0)$ & 3.1 \\
\hline $65-74$ & $97(2.7)$ & 2.7 & $53(5.0)$ & 1.3 & $150(3.2)$ & 2.0 \\
\hline $75-84$ & $44(1.2)$ & 2.6 & $38(3.6)$ & 1.7 & $82(1.8)$ & 2.1 \\
\hline$\geq 85$ & $16(<1.0)$ & $* *$ & $15(1.4)$ & $* *$ & $31(<1.0)$ & 1.8 \\
\hline Unknown & $1(<1.0)$ & ** & $1(<1.0)$ & ** & $2(<1.0)$ & ** \\
\hline Total & $3,629(100)$ & 7.7 & $1,052(100)$ & 2.2 & $4,681(100)$ & 4.9 \\
\hline \multicolumn{7}{|l|}{ Race/Ethnicity } \\
\hline White, non-Hispanic & $1,013(27.9)$ & 3.1 & $543(51.6)$ & 1.6 & $1,556(33.2)$ & 2.4 \\
\hline Black, non-Hispanic & 2,097 (57.8) & 29.8 & $372(35.4)$ & 4.8 & $2,469(52.7)$ & 16.7 \\
\hline American Indian/Alaska Native & $68(1.9)$ & 12.3 & $19(1.8)$ & $* *$ & $87(1.9)$ & 7.7 \\
\hline Asian/Pacific Islander & $40(1.1)$ & 2.1 & $23(2.2)$ & 1.1 & $63(1.3)$ & 1.6 \\
\hline Hispanic ${ }^{\dagger \dagger}$ & $365(10.1)$ & 7.0 & $83(7.9)$ & 1.7 & $448(9.6)$ & 4.4 \\
\hline Other & $20(<1.0)$ & $* *$ & $4(<1.0)$ & $* *$ & $24(<1.0)$ & $* *$ \\
\hline Unknown & $26(<1.0)$ & $* *$ & $8(<1.0)$ & $* *$ & $34(<1.0)$ & $* *$ \\
\hline Total & $3,629(100)$ & 7.7 & $1,052(100)$ & 2.2 & $4,681(100)$ & 4.9 \\
\hline
\end{tabular}

* Percentages might not total $100 \%$ due to rounding.

+ Per 100,000 population.

$\S$ The term legal intervention does not denote the lawfulness or legality of the circumstances surrounding the death.

" Alaska, Colorado, Georgia, Kentucky, Maryland, Massachusetts, North Carolina, New Jersey, New Mexico, Ohio, Oklahoma, Oregon, Rhode Island, South Carolina, Utah, Virginia, and Wisconsin.

** Rate is not reported when number of deaths is $<20$ or when age or race/ethnicity is other or unknown.

${ }^{+\dagger}$ Includes persons of any race. 
TABLE 13. Number and percentage* of homicides/legal intervention ${ }^{\dagger}$ deaths, by decedent's sex, method used, and location where injury occurred - National Violent Death Reporting System, 17 states, $\$ 2013$

\begin{tabular}{|c|c|c|c|}
\hline & Male & Female & Total \\
\hline Characteristic & No. (\%) & No. (\%) & No. (\%) \\
\hline \multicolumn{4}{|l|}{ Method } \\
\hline Firearm & $2,606(71.8)$ & $513(48.8)$ & $3,119(66.6)$ \\
\hline Sharp instrument & $368(10.1)$ & $151(14.4)$ & $519(11.1)$ \\
\hline Blunt instrument & $184(5.1)$ & $79(7.5)$ & $263(5.6)$ \\
\hline Personal weapons (e.g., hands, feet, fists) & $166(4.6)$ & $55(5.2)$ & $221(4.7)$ \\
\hline Hanging/strangulation/suffocation & $63(1.7)$ & $93(8.8)$ & $156(3.3)$ \\
\hline Motor vehicle (e.g., car, bus, motorcycle, other transport vehicle) & $17(<1.0)$ & $13(1.2)$ & $30(<1.0)$ \\
\hline Fire/burns & $17(<1.0)$ & $9(<1.0)$ & $26(<1.0)$ \\
\hline Poisoning & $8(<1.0)$ & $9(<1.0)$ & $17(<1.0)$ \\
\hline Intentional neglect & $7(<1.0)$ & $8(<1.0)$ & $15(<1.0)$ \\
\hline Fall & $5(<1.0)$ & $4(<1.0)$ & $9(<1.0)$ \\
\hline Drowning & $2(<1.0)$ & $3(<1.0)$ & $5(<1.0)$ \\
\hline Other (single method) & $15(<1.0)$ & $10(1.0)$ & $25(<1.0)$ \\
\hline Unknown & $171(4.7)$ & $105(10.0)$ & $276(5.9)$ \\
\hline Total & $3,629(100)$ & $1,052(100)$ & $4,681(100)$ \\
\hline \multicolumn{4}{|l|}{ Location } \\
\hline House or apartment & $1,659(45.7)$ & $772(73.4)$ & $2,431(51.9)$ \\
\hline Street or highway & $868(23.9)$ & $63(6.0)$ & $931(19.9)$ \\
\hline Motor vehicle & $257(7.1)$ & $58(5.5)$ & $315(6.7)$ \\
\hline Parking lot/public garage/public transport & $166(4.6)$ & $16(1.5)$ & $182(3.9)$ \\
\hline Commercial/retail Area & $128(3.5)$ & $12(1.1)$ & $140(3.0)$ \\
\hline Bar/nightclub & $94(2.6)$ & $5(<1.0)$ & $99(2.1)$ \\
\hline Natural area & $57(1.6)$ & $23(2.2)$ & $80(1.7)$ \\
\hline Hotel/motel & $35(1.0)$ & $15(1.4)$ & $50(1.1)$ \\
\hline Park, playground, sports/athletic area & $39(1.1)$ & $8(<1.0)$ & $47(1.0)$ \\
\hline Jail/prison & $41(1.1)$ & $0(0)$ & $41(<1.0)$ \\
\hline Abandoned house/building/warehouse & $10(<1.0)$ & $5(<1.0)$ & $15(<1.0)$ \\
\hline Hospital or medical facility & $5(<1.0)$ & $6(<1.0)$ & $11(<1.0)$ \\
\hline Industrial or construction area & $10(<1.0)$ & $1(<1.0)$ & $11(<1.0)$ \\
\hline Preschool/school/college/school bus & $8(<1.0)$ & $2(<1.0)$ & $10(<1.0)$ \\
\hline Supervised residential facility & $5(<1.0)$ & $2(<1.0)$ & $7(<1.0)$ \\
\hline Office building & $2(<1.0)$ & $4(<1.0)$ & $6(<1.0)$ \\
\hline Farm & $1(<1.0)$ & $2(<1.0)$ & $3(<1.0)$ \\
\hline Railroad tracks & $1(<1.0)$ & $0(0)$ & $1(<1.0)$ \\
\hline Other & $52(1.4)$ & $11(1.0)$ & $63(1.3)$ \\
\hline Unknown & $191(5.3)$ & $47(4.5)$ & $238(5.1)$ \\
\hline Total & $3,629(100)$ & $1,052(100)$ & $4,681(100)$ \\
\hline
\end{tabular}

* Percentages might not total $100 \%$ due to rounding.

† The term legal intervention does not denote the lawfulness or legality of the circumstances surrounding the death.

$\S$ Alaska, Colorado, Georgia, Kentucky, Maryland, Massachusetts, North Carolina, New Jersey, New Mexico, Ohio, Oklahoma, Oregon, Rhode Island, South Carolina, Utah, Virginia, and Wisconsin. 
TABLE 14. Number* and percentage of homicide/legal intervention ${ }^{\dagger}$ decedents tested for alcohol and drugs and whose results were positive, $\$$ by toxicology variable — National Violent Death Reporting System, 17 states, ^ 2013

\begin{tabular}{lrrr}
\hline & \multicolumn{1}{c}{ Tested } & & Positive \\
\cline { 2 - 2 } Toxicology variable & No. $(\%)$ & & No. $(\%)$ \\
\hline BAC** & $2,895(61.8)$ & & $1,102(38.1)$ \\
Alcohol $<0.08 \mathrm{~g} / \mathrm{dL}$ & & $375(34.0)$ \\
Alcohol $\geq 0.08 \mathrm{~g} / \mathrm{dL}$ & & & $701(63.6)$ \\
Alcohol positive, level unknown & & & $26(2.4)$ \\
Amphetamines & $1,781(38.0)$ & & $198(11.1)$ \\
Anticonvulsants & $1,029(22.0)$ & & $56(5.4)$ \\
Antidepressants & $1,078(23.0)$ & & $120(11.1)$ \\
Antipsychotics & $1,066(22.8)$ & & $21(2.0)$ \\
Barbiturates & $1,391(29.7)$ & & $16(1.2)$ \\
Benzodiazepines & $1,552(33.2)$ & & $190(12.2)$ \\
Carbon monoxide & $654(14.0)$ & & $49(7.5)$ \\
Cocaine & $1,980(42.3)$ & & $310(15.7)$ \\
Marijuana & $1,630(34.8)$ & & $693(42.5)$ \\
Muscle relaxants & $1,099(23.5)$ & & $18(1.6)$ \\
Opiates & $1,933(41.3)$ & & $353(18.3)$ \\
Other drugs/substances ${ }^{\dagger \dagger}$ & $675(14.4)$ & $665(98.5)$ \\
\hline
\end{tabular}

* No. decedents $=4,681$.

† The term legal intervention does not denote the lawfulness or legality of the circumstances surrounding the death.

$\S$ Percentage is of decedents tested for toxicology variable.

" Alaska, Colorado, Georgia, Kentucky, Maryland, Massachusetts, North Carolina, New Jersey, New Mexico, Ohio, Oklahoma, Oregon, Rhode Island, South Carolina, Utah, Virginia, and Wisconsin.

** $B A C \geq 0.08 \mathrm{~g} / \mathrm{dL}$ is over the legal limit in all states and is used as the standard for intoxication.

${ }^{\dagger+}$ Other drugs/substances indicated if any results were positive; levels for these drugs/substances are not measured. 
TABLE 15. Number* and percentage ${ }^{\dagger}$ of homicides/legal intervention ${ }^{\S}$ deaths, by precipitating circumstance and decedent's sex — National Violent Death Reporting System, 17 states, ${ }^{\mathfrak{R}} 2013$

\begin{tabular}{|c|c|c|c|}
\hline & Male & Female & Total \\
\hline Precipitating circumstance & No. (\%) & No. (\%) & No. (\%) \\
\hline \multicolumn{4}{|l|}{ Mental health/Substance abuse } \\
\hline Other substance abuse problem (excludes alcohol) & $279(10.1)$ & $80(8.8)$ & $359(9.8)$ \\
\hline Current diagnosed mental health problem & $124(4.5)$ & $53(5.8)$ & $177(4.8)$ \\
\hline History of ever being treated for a mental health problem & 99 (3.6) & $48(5.3)$ & $147(4.0)$ \\
\hline Alcohol problem & $115(4.2)$ & $26(2.9)$ & $141(3.8)$ \\
\hline Current mental health treatment & $66(2.4)$ & $40(4.4)$ & $106(2.9)$ \\
\hline Current depressed mood & $22(<1.0)$ & $8(<1.0)$ & $30(<1.0)$ \\
\hline Other addiction (e.g., gambling, sex) & $4(<1.0)$ & $2(<1.0)$ & $6(<1.0)$ \\
\hline \multicolumn{4}{|l|}{ Interpersonal } \\
\hline Intimate partner problem & $258(9.3)$ & $433(47.5)$ & $691(18.8)$ \\
\hline Family relationship problem & $132(4.8)$ & $62(6.8)$ & $194(5.3)$ \\
\hline Other relationship problem (nonintimate) & $127(4.6)$ & $25(2.7)$ & $152(4.1)$ \\
\hline Jealousy (lovers' triangle) & $60(2.2)$ & $48(5.3)$ & $108(2.9)$ \\
\hline Victim of interpersonal violence within past month & $34(1.2)$ & $66(7.2)$ & $100(2.7)$ \\
\hline Perpetrator of interpersonal violence within past month & $84(3.0)$ & $6(<1.0)$ & $90(2.4)$ \\
\hline \multicolumn{4}{|l|}{ Life stressor } \\
\hline Argument or conflict & $954(34.5)$ & $267(29.3)$ & $1,221(33.2)$ \\
\hline Physical fight (two people, not a brawl) & $367(13.3)$ & $48(5.3)$ & $415(11.3)$ \\
\hline Crisis within previous or upcoming 2 weeks & $200(7.2)$ & $106(11.6)$ & $306(8.3)$ \\
\hline History of child abuse/neglect & $30(1.1)$ & $19(2.1)$ & 49 (1.3) \\
\hline \multicolumn{4}{|l|}{ Crime and criminal activity } \\
\hline Precipitated by another crime & $1,188(43.0)$ & $259(28.4)$ & $1,447(39.4)$ \\
\hline Crime in progress** & $847(71.3)$ & $164(63.3)$ & $1,011(69.9)$ \\
\hline Drug involvement & $420(15.2)$ & $48(5.3)$ & 468 (12.7) \\
\hline Gang related & $183(6.6)$ & $17(1.9)$ & $200(5.4)$ \\
\hline Terrorist attack & $2(<1.0)$ & $1(<1.0)$ & $3(<1.0)$ \\
\hline \multicolumn{4}{|l|}{ Homicide/Legal intervention event } \\
\hline Victim used a weapon & $333(12.1)$ & $20(2.2)$ & $353(9.6)$ \\
\hline Suspect was mentally ill & $56(2.0)$ & $48(5.3)$ & $104(2.8)$ \\
\hline Brawl & $84(3.0)$ & $6(<1.0)$ & $90(2.4)$ \\
\hline Victim was a bystander & $35(1.3)$ & $19(2.1)$ & $54(1.5)$ \\
\hline Random violence & $33(1.2)$ & $9(1.0)$ & $42(1.1)$ \\
\hline Victim was an intervener assisting a crime victim & $25(<1.0)$ & $5(<1.0)$ & $30(<1.0)$ \\
\hline Prostitution & $12(<1.0)$ & $12(1.3)$ & $24(<1.0)$ \\
\hline Stalking & $3(<1.0)$ & $9(1.0)$ & $12(<1.0)$ \\
\hline Victim was a police officer on duty & $8(<1.0)$ & $0(0)$ & $8(<1.0)$ \\
\hline \multicolumn{4}{|l|}{ Homicide-only event $^{\dagger \dagger}$} \\
\hline Caretaker abuse/neglect led to death & $99(3.9)$ & $78(8.7)$ & $177(5.1)$ \\
\hline Justifiable self-defense & $97(3.8)$ & $5(<1.0)$ & $102(3.0)$ \\
\hline Drive-by shooting & $84(3.3)$ & $10(1.1)$ & $94(2.7)$ \\
\hline Walk-by assault & $72(2.8)$ & $6(<1.0)$ & $78(2.3)$ \\
\hline Mercy killing & $2(<1.0)$ & $3(<1.0)$ & $5(<1.0)$ \\
\hline Hate crime & $0(0)$ & $0(0)$ & $0(0)$ \\
\hline Total deaths with precipitating circumstances & $2,763(100)$ & $911(100)$ & $3,674(100)$ \\
\hline
\end{tabular}

* Includes deaths with one or more precipitating circumstances. Circumstances are unknown for 1,007 decedents ( 866 males, 141 females). Numbers do not equal the sums of the columns because a death could have had more than one precipitating circumstance.

t Denominator includes only those deaths with one or more precipitating circumstances. Sums of percentages in columns exceed $100 \%$ because a death could have had more than one precipitating circumstance.

$\S$ The term legal intervention does not denote the lawfulness or legality of the circumstances surrounding the death.

" Alaska, Colorado, Georgia, Kentucky, Maryland, Massachusetts, North Carolina, New Jersey, New Mexico, Ohio, Oklahoma, Oregon, Rhode Island, South Carolina, Utah, Virginia, and Wisconsin.

** Denominator includes only those decedents involved in an incident that was precipitated by another crime.

t+ Includes 3,456 deaths (2,559 males, 897 females). 
TABLE 18. Number, percentage* and rate ${ }^{\dagger}$ of legal intervention ${ }^{\S}$ deaths, by decedent's sex, age group, and race/ethnicity — National Violent Death Reporting System, 17 states, 92013

\begin{tabular}{|c|c|c|c|c|c|c|}
\hline \multirow[b]{2}{*}{ Characteristic } & \multicolumn{2}{|c|}{ Male } & \multicolumn{2}{|c|}{ Female } & \multicolumn{2}{|c|}{ Total } \\
\hline & No. (\%) & Rate & No. (\%) & Rate & No. (\%) & Rate \\
\hline \multicolumn{7}{|l|}{ Age group (yrs) } \\
\hline$<1$ & $0(0)$ & ** & $0(0)$ & ** & $0(0)$ & ** \\
\hline $1-4$ & $0(0)$ & $* *$ & $0(0)$ & $* *$ & $0(0)$ & $* *$ \\
\hline $5-9$ & $0(0)$ & ** & $0(0)$ & ** & $0(0)$ & ** \\
\hline $10-14$ & $0(0)$ & $* *$ & $0(0)$ & $* *$ & $0(0)$ & ** \\
\hline $15-19$ & $12(5.8)$ & ** & $0(0)$ & ** & $12(5.4)$ & ** \\
\hline $20-24$ & $35(16.8)$ & 1.0 & $2(14.3)$ & ** & $37(16.7)$ & 0.5 \\
\hline $25-29$ & $23(11.1)$ & 0.7 & $0(0)$ & $* *$ & $23(10.4)$ & 0.4 \\
\hline $30-34$ & $35(16.8)$ & 1.1 & $3(21.4)$ & ** & $38(17.1)$ & 0.6 \\
\hline $35-44$ & $46(22.1)$ & 0.7 & $5(35.7)$ & $* *$ & $51(23.0)$ & 0.4 \\
\hline $45-54$ & $32(15.4)$ & 0.5 & $3(21.4)$ & ** & $35(15.8)$ & 0.3 \\
\hline $55-64$ & $20(9.6)$ & 0.3 & $1(7.1)$ & ** & $21(9.5)$ & 0.2 \\
\hline $65-74$ & $3(1.4)$ & $* *$ & $0(0)$ & $* *$ & $3(1.4)$ & ** \\
\hline $75-84$ & $2(1.0)$ & ** & $0(0)$ & $* *$ & $2(<1.0)$ & ** \\
\hline$\geq 85$ & $0(0)$ & ** & $0(0)$ & ** & $0(0)$ & ** \\
\hline Unknown & $0(0)$ & $* *$ & $0(0)$ & $* *$ & $0(0)$ & $* *$ \\
\hline Total & $208(100)$ & 0.4 & $14(100)$ & ** & $222(100)$ & 0.2 \\
\hline \multicolumn{7}{|l|}{ Race/Ethnicity } \\
\hline White, non-Hispanic & $91(43.8)$ & 0.3 & $7(50.0)$ & $* *$ & $98(44.1)$ & 0.1 \\
\hline Black, non-Hispanic & $81(38.9)$ & 1.2 & $4(28.6)$ & ** & $85(38.3)$ & 0.6 \\
\hline American Indian/Alaska Native & $6(2.9)$ & ** & $0(0)$ & ** & $6(2.7)$ & ** \\
\hline Asian/Pacific Islander & $0(0)$ & $* *$ & $1(7.1)$ & ** & $1(<1.0)$ & $* *$ \\
\hline Hispanic ${ }^{\dagger+}$ & $28(13.5)$ & 0.5 & $2(14.3)$ & ** & $30(13.5)$ & 0.3 \\
\hline Other & $2(1.0)$ & ** & $0(0)$ & ** & $2(<1.0)$ & $* *$ \\
\hline Unknown & $0(0)$ & ** & $0(0)$ & ** & $0(0)$ & ** \\
\hline Total & $208(100)$ & 0.4 & $14(100)$ & ** & $222(100)$ & 0.2 \\
\hline
\end{tabular}

* Percentages might not total $100 \%$ due to rounding.

+ Per 100,000 population.

$\S$ The term legal intervention does not denote the lawfulness or legality of the circumstances surrounding the death.

" Alaska, Colorado, Georgia, Kentucky, Maryland, Massachusetts, North Carolina, New Jersey, New Mexico, Ohio, Oklahoma, Oregon, Rhode Island, South Carolina, Utah, Virginia, and Wisconsin.

** Rate is not reported when number of deaths is $<20$ or when age or race/ethnicity is other or unknown.

${ }^{+\dagger}$ Includes persons of any race. 
TABLE 19. Number and percentage* of legal intervention ${ }^{\dagger}$ deaths, by decedent's sex, method used, and location where injury occurred National Violent Death Reporting System, 17 states, $\$ 2013$

\begin{tabular}{|c|c|c|c|}
\hline & Male & Female & Total \\
\hline Characteristic & No. (\%) & No. (\%) & No. (\%) \\
\hline \multicolumn{4}{|l|}{ Method } \\
\hline Firearm & $192(92.3)$ & $13(92.9)$ & $205(92.3)$ \\
\hline Motor vehicle (e.g., car, bus, motorcycle, other transport vehicle) & $1(<1.0)$ & $1(7.1)$ & $2(<1.0)$ \\
\hline Poisoning & $2(1.0)$ & $0(0)$ & $2(<1.0)$ \\
\hline Blunt instrument & $1(<1.0)$ & $0(0)$ & $1(0.5)$ \\
\hline Hanging/strangulation/suffocation & $1(<1.0)$ & $0(0)$ & $1(0.5)$ \\
\hline Sharp instrument & $1(<1.0)$ & $0(0)$ & $1(0.5)$ \\
\hline Drowning & $0(0)$ & $0(0)$ & $0(0)$ \\
\hline Fall & $0(0)$ & $0(0)$ & $0(0)$ \\
\hline Fire/burns & $0(0)$ & $0(0)$ & $0(0)$ \\
\hline Intentional neglect & $0(0)$ & $0(0)$ & $0(0)$ \\
\hline Personal weapons (e.g., hands, feet, fists) & $0(0)$ & $0(0)$ & $0(0)$ \\
\hline Other (single method) & $2(1.0)$ & $0(0)$ & $2(<1.0)$ \\
\hline Unknown & $8(3.8)$ & $0(0)$ & $8(3.6)$ \\
\hline Total & $208(100)$ & $14(100)$ & $222(100)$ \\
\hline \multicolumn{4}{|l|}{ Location } \\
\hline House or apartment & $86(41.3)$ & $6(42.9)$ & 92 (41.4) \\
\hline Street or highway & $53(25.5)$ & $3(21.4)$ & $56(25.2)$ \\
\hline Motor vehicle & $15(7.2)$ & $4(28.6)$ & $19(8.6)$ \\
\hline Commercial/retail Area & $8(3.8)$ & $1(7.1)$ & $9(4.1)$ \\
\hline Parking lot/public garage/public transport & $9(4.3)$ & $0(0)$ & $9(4.1)$ \\
\hline Natural area & $8(3.8)$ & $0(0)$ & $8(3.6)$ \\
\hline Jail/prison & $4(1.9)$ & $0(0)$ & $4(1.8)$ \\
\hline Park, playground, sports/athletic area & $4(1.9)$ & $0(0)$ & $4(1.8)$ \\
\hline Bar/nightclub & $3(1.4)$ & $0(0)$ & $3(1.4)$ \\
\hline Hotel/motel & $3(1.4)$ & $0(0)$ & $3(1.4)$ \\
\hline Preschool/school/college/school bus & $3(1.4)$ & $0(0)$ & $3(1.4)$ \\
\hline Hospital or medical facility & $1(<1.0)$ & $0(0)$ & $1(<1.0)$ \\
\hline Office building & $1(<1.0)$ & $0(0)$ & $1(<1.0)$ \\
\hline Supervised residential facility & $1(<1.0)$ & $0(0)$ & $1(<1.0)$ \\
\hline Abandoned house/building/warehouse & $0(0)$ & $0(0)$ & $0(0)$ \\
\hline Farm & $0(0)$ & $0(0)$ & $0(0)$ \\
\hline Industrial or construction area & $0(0)$ & $0(0)$ & $0(0)$ \\
\hline Railroad tracks & $0(0)$ & $0(0)$ & $0(0)$ \\
\hline Other & $3(1.4)$ & $0(0)$ & $3(1.4)$ \\
\hline Unknown & $6(2.9)$ & $0(0)$ & $6(2.7)$ \\
\hline Total & $208(100)$ & $14(100)$ & $222(100)$ \\
\hline
\end{tabular}

* Percentages might not total $100 \%$ due to rounding.

t The term legal intervention does not denote the lawfulness or legality of the circumstances surrounding the death.

$\S$ Alaska, Colorado, Georgia, Kentucky, Maryland, Massachusetts, North Carolina, New Jersey, New Mexico, Ohio, Oklahoma, Oregon, Rhode Island, South Carolina, Utah, Virginia, and Wisconsin. 
TABLE 20. Number* and percentage of legal intervention ${ }^{\dagger}$ decedents tested for alcohol and drugs and whose results were positive, ${ }^{\S}$ by toxicology variable - National Violent Death Reporting System, 17 states, 2013

\begin{tabular}{lrrr}
\hline & Tested & & Positive \\
\cline { 2 - 2 } Toxicology variable & No. (\%) & & No. (\%) \\
\hline BAC** & $160(72.1)$ & & $63(39.4)$ \\
Alcohol $<0.08 \mathrm{~g} / \mathrm{dL}$ & & $14(22.2)$ \\
Alcohol $\geq 0.08 \mathrm{~g} / \mathrm{dL}$ & & $48(76.2)$ \\
Alcohol positive, level unknown & & $1(1.6)$ \\
Amphetamines & $103(46.4)$ & & $26(25.2)$ \\
Anticonvulsants & $70(31.5)$ & & $4(5.7)$ \\
Antidepressants & $75(33.8)$ & & $17(22.7)$ \\
Antipsychotics & $64(28.8)$ & & $2(3.1)$ \\
Barbiturates & $89(40.1)$ & & $2(2.2)$ \\
Benzodiazepines & $118(53.2)$ & & $24(20.3)$ \\
Carbon monoxide & $28(12.6)$ & & $0(0)$ \\
Cocaine & $131(59.0)$ & & $20(15.3)$ \\
Marijuana & $96(43.2)$ & & $36(37.5)$ \\
Muscle relaxants & $58(26.1)$ & & $1(1.7)$ \\
Opiates & $131(59.0)$ & & $24(18.3)$ \\
Other drugs/substances ${ }^{\dagger \dagger}$ & $53(23.9)$ & $53(100)$ \\
\hline
\end{tabular}

Abbreviation: $\mathrm{BAC}=$ blood alcohol concentration.

* No. decedents $=222$.

† The term legal intervention does not denote the lawfulness or legality of the circumstances surrounding the death.

$\S$ Percentage is of decedents tested for toxicology variable.

१ Alaska, Colorado, Georgia, Kentucky, Maryland, Massachusetts, North Carolina, New Jersey, New Mexico, Ohio, Oklahoma, Oregon, Rhode Island, South Carolina, Utah, Virginia, and Wisconsin.

** BAC $\geq 0.08 \mathrm{~g} / \mathrm{dL}$ is over the legal limit in all states and is used as the standard for intoxication.

t† Other drugs/substances indicated if any results were positive; levels for these drugs/substances are not measured. 
TABLE 21. Number* and percentage ${ }^{\dagger}$ of legal intervention ${ }^{\S}$ deaths, by precipitating circumstance and decedent's sex — National Violent Death Reporting System, 17 states, ${ }^{\text {ๆ }} 2013$

\begin{tabular}{|c|c|c|c|}
\hline & Male & Female & Total \\
\hline Precipitating circumstance & No. (\%) & No. (\%) & No. (\%) \\
\hline \multicolumn{4}{|l|}{ Mental health/Substance abuse } \\
\hline Current diagnosed mental health problem & $41(20.1)$ & $2(14.3)$ & $43(19.7)$ \\
\hline History of ever being treated for a mental health problem & $37(18.1)$ & $1(7.1)$ & $38(17.4)$ \\
\hline Other substance abuse problem (excludes alcohol) & $33(16.2)$ & $2(14.3)$ & $35(16.1)$ \\
\hline Current mental health treatment & $20(9.8)$ & $0(0)$ & $20(9.2)$ \\
\hline Alcohol problem & $18(8.8)$ & $0(0)$ & $18(8.3)$ \\
\hline Current depressed mood & $12(5.9)$ & $0(0)$ & $12(5.5)$ \\
\hline Other addiction (e.g., gambling, sex) & $0(0)$ & $0(0)$ & $0(0)$ \\
\hline \multicolumn{4}{|l|}{ Interpersonal } \\
\hline Perpetrator of interpersonal violence within past month & $26(12.7)$ & $1(7.1)$ & 27 (12.4) \\
\hline Intimate partner violence-related & $22(10.8)$ & $1(7.1)$ & $23(10.6)$ \\
\hline Family relationship problem & $11(5.4)$ & $0(0)$ & $11(5.0)$ \\
\hline Other relationship problem (nonintimate) & $8(3.9)$ & $0(0)$ & $8(3.7)$ \\
\hline Jealousy (lovers' triangle) & $3(1.5)$ & $1(7.1)$ & $4(1.8)$ \\
\hline Victim of interpersonal violence within past month & $1(<1.0)$ & $0(0)$ & $1(<1.0)$ \\
\hline \multicolumn{4}{|l|}{ Life stressor } \\
\hline Crisis within previous or upcoming 2 weeks & $35(17.2)$ & $2(14.3)$ & $37(17.0)$ \\
\hline Argument or conflict & $31(15.2)$ & $0(0)$ & $31(14.2)$ \\
\hline Physical fight (two people, not a brawl) & $12(5.9)$ & $0(0)$ & $12(5.5)$ \\
\hline History of child abuse/neglect & $0(0)$ & $0(0)$ & $0(0)$ \\
\hline \multicolumn{4}{|l|}{ Crime and criminal activity } \\
\hline Precipitated by another crime & $178(87.3)$ & $13(92.9)$ & $191(87.6)$ \\
\hline Crime in progress** & $133(74.7)$ & $9(69.2)$ & $142(74.3)$ \\
\hline Drug involvement & $15(7.4)$ & $2(14.3)$ & $17(7.8)$ \\
\hline Gang related & $3(1.5)$ & $0(0)$ & $3(1.4)$ \\
\hline Terrorist attack & $1(<1.0)$ & $0(0)$ & $1(<1.0)$ \\
\hline \multicolumn{4}{|l|}{ Homicide/Legal intervention event } \\
\hline Victim used a weapon & $149(73.0)$ & $9(64.3)$ & $158(72.5)$ \\
\hline Brawl & $2(1.0)$ & $0(0)$ & $2(<1.0)$ \\
\hline Victim was a bystander & $0(0)$ & $1(7.1)$ & $1(<1.0)$ \\
\hline Victim was a police officer on duty & $0(0)$ & $0(0)$ & $0(0)$ \\
\hline Victim was an intervener assisting a crime victim & $0(0)$ & $0(0)$ & $0(0)$ \\
\hline Suspect was mentally ill & $0(0)$ & $0(0)$ & $0(0)$ \\
\hline Random violence & $0(0)$ & $0(0)$ & $0(0)$ \\
\hline Stalking & $0(0)$ & $0(0)$ & $0(0)$ \\
\hline Prostitution & $0(0)$ & $0(0)$ & $0(0)$ \\
\hline Total deaths with precipitating circumstances & $204(100)$ & $14(100)$ & $218(100)$ \\
\hline
\end{tabular}

* Includes deaths with one or more precipitating circumstances. Circumstances are unknown for four decedents (four males, no females). Numbers do not equal the sums of the columns because a death could have had more than one precipitating circumstance.

${ }^{\dagger}$ Denominator includes only those deaths with one or more precipitating circumstances. Sums of percentages in columns exceed $100 \%$ because a death could have more than one precipitating circumstance.

$\S$ The term legal intervention does not denote the lawfulness or legality of the circumstances surrounding the death.

" Alaska, Colorado, Georgia, Kentucky, Maryland, Massachusetts, North Carolina, New Jersey, New Mexico, Ohio, Oklahoma, Oregon, Rhode Island, South Carolina, Utah, Virginia, and Wisconsin.

** Denominator includes only those decedents involved in an incident that was precipitated by another crime. 
TABLE 22. Number* and percentage ${ }^{\dagger}$ of legal intervention ${ }^{\S}$ deaths precipitated by another crime, by type of crime - National Violent Death Reporting System, 17 states, " 2013

\begin{tabular}{lr}
\hline Type of crime & No. $(\%)$ \\
\hline Assault, homicide & $130(68.1)$ \\
Robbery & $19(9.9)$ \\
Motor vehicle theft & $10(5.2)$ \\
Burglary & $9(4.7)$ \\
Drug trade & $8(4.2)$ \\
Rape, sexual assault & $2(1.0)$ \\
Other crime & $57(29.8)$ \\
Unknown & $11(5.8)$ \\
Total deaths precipitated by another crime & $191(100)$ \\
\hline
\end{tabular}

* Includes deaths precipitated by another crime. Number does not equal the sum of the column because a death could have been precipitated by more than one other crime.

t Denominator includes only those decedents involved in an incident that was precipitated by another crime. Sum of percentage in the colum exceeds $100 \%$ because a death could have been precipitated by more than one other crime.

$\S$ The term legal intervention does not denote the lawfulness or legality of the circumstances surrounding the death.

" Alaska, Colorado, Georgia, Kentucky, Maryland, Massachusetts, North Carolina, New Jersey, New Mexico, Ohio, Oklahoma, Oregon, Rhode Island, South Carolina, Utah, Virginia, and Wisconsin.

TABLE 23. Number* and percentage ${ }^{\dagger}$ of legal intervention ${ }^{\S}$ decedents who experienced a recent crisis, by type of crisis and decedent's sex — National Violent Death Reporting System, 17 states, " 2013

\begin{tabular}{|c|c|c|c|}
\hline & Male & Female & Total \\
\hline Type of crisis & No. (\%) & No. $(\%)$ & No. (\%) \\
\hline Family relationship problem & $6(17.1)$ & $0(0)$ & $6(16.2)$ \\
\hline Current diagnosed mental health problem & $4(11.4)$ & $0(0)$ & $4(10.8)$ \\
\hline Other substance abuse problem & $2(5.7)$ & $0(0)$ & $2(5.4)$ \\
\hline Other relationship problem & $2(5.7)$ & $0(0)$ & $2(5.4)$ \\
\hline Alcohol problem & $1(2.9)$ & $0(0)$ & $1(2.7)$ \\
\hline Jealousy (lovers' triangle) & $0(0)$ & $1(50.0)$ & $1(2.7)$ \\
\hline Other addiction (e.g., gambling, sex) & $0(0)$ & $0(0)$ & $0(0)$ \\
\hline Stalking & $0(0)$ & $0(0)$ & $0(0)$ \\
\hline Prostitution & $0(0)$ & $0(0)$ & $0(0)$ \\
\hline Other crisis & $16(45.7)$ & $1(50.0)$ & $17(45.9)$ \\
\hline Total decedents who experienced a recent crisis & $35(100)$ & $2(100)$ & $37(100)$ \\
\hline
\end{tabular}

* Of the 222 legal intervention decedents, 37 decedents (16.6\%; 35 males, 2 females) experienced one or more crises within the previous or upcoming 2 weeks. Numbers do not equal the sums of the columns because a decedent could have experienced more than one crisis.

† Denominator includes only those decedents who experienced one or more crises within the previous or upcoming 2 weeks. Sums of percentages in columns exceed $100 \%$ because a decedent could have experienced more than one crisis.

$\S$ The term legal intervention does not denote the lawfulness or legality of the circumstances surrounding the death.

I Alaska, Colorado, Georgia, Kentucky, Maryland, Massachusetts, North Carolina, New Jersey, New Mexico, Ohio, Oklahoma, Oregon, Rhode Island, South Carolina, Utah, Virginia, and Wisconsin. 
TABLE 24. Number, ${ }^{*}$ percentage, ${ }^{\dagger}$ and rate $^{\S}$ of deaths of undetermined intent," by method used and month in which death occurred National Violent Death Reporting System, 17 states, ${ }^{* *} 2013$

\begin{tabular}{|c|c|c|}
\hline Characteristic & No. (\%) & Rate \\
\hline \multicolumn{3}{|l|}{ Method } \\
\hline Poisoning & $1,145(67.4)$ & 1.2 \\
\hline Firearm & $78(4.6)$ & 0.1 \\
\hline Blunt instrument & $61(3.6)$ & 0.1 \\
\hline Drowning & $53(3.1)$ & 0.1 \\
\hline Fall & $39(2.3)$ & 0 \\
\hline Hanging/strangulation/suffocation & $36(2.1)$ & 0 \\
\hline Fire/burns & $31(1.8)$ & 0 \\
\hline $\begin{array}{l}\text { Motor vehicle (e.g., car, bus, motorcycle, } \\
\text { other transport vehicle) }\end{array}$ & $28(1.6)$ & 0 \\
\hline Personal weapons (e.g., hands, feet, fists) & $7(<1.0)$ & t† \\
\hline Sharp instrument & $5(<1.0)$ & t† \\
\hline Intentional neglect & $2(<1.0)$ & †† \\
\hline Other (single method) & $14(<1.0)$ & t† \\
\hline Unknown & $199(11.7)$ & 0.2 \\
\hline Total & $1,698(100)$ & 1.8 \\
\hline \multicolumn{3}{|l|}{ Month } \\
\hline January & $146(8.6)$ & 0.2 \\
\hline February & $108(6.4)$ & 0.1 \\
\hline March & $142(8.4)$ & 0.1 \\
\hline April & $142(8.4)$ & 0.1 \\
\hline May & $144(8.5)$ & 0.2 \\
\hline June & $162(9.5)$ & 0.2 \\
\hline July & $150(8.8)$ & 0.2 \\
\hline August & $141(8.3)$ & 0.1 \\
\hline September & $124(7.3)$ & 0.1 \\
\hline October & $134(7.9)$ & 0.1 \\
\hline November & $133(7.8)$ & 0.1 \\
\hline December & $155(9.1)$ & 0.2 \\
\hline Unknown & $17(1.0)$ & †† \\
\hline Total & $1,698(100)$ & 1.8 \\
\hline
\end{tabular}

* No. incidents $=1,688$; no. deaths $=1,698$.

+ Percentages might not total $100 \%$ due to rounding.

$\S$ Per 100,000 population.

" Death that results from the use of force or power against oneself or another person for which evidence indicating one manner of death is no more compelling than evidence indicating another.

** Alaska, Colorado, Georgia, Kentucky, Maryland, Massachusetts, North Carolina, New Jersey, New Mexico, Ohio, Oklahoma, Oregon, Rhode Island, South Carolina, Utah, Virginia, and Wisconsin.

${ }^{t+}$ Rate is not reported when number of deaths is $<20$. 
TABLE 25. Number, percentage,* and rate ${ }^{\dagger}$ of deaths of undetermined intent, $\$$ by decedent's sex, age group, race/ethnicity, and marital status — National Violent Death Reporting System, 17 states, "ी 2013

\begin{tabular}{|c|c|c|c|c|c|c|}
\hline \multirow[b]{2}{*}{ Characteristic } & \multicolumn{2}{|c|}{ Male } & \multicolumn{2}{|c|}{ Female } & \multicolumn{2}{|c|}{ Total } \\
\hline & No. (\%) & Rate & No. (\%) & Rate & No. (\%) & Rate \\
\hline \multicolumn{7}{|l|}{ Age group (yrs) } \\
\hline$<1<$ & $27(2.5)$ & 4.5 & $11(1.8)$ & $* *$ & $38(2.2)$ & 3.2 \\
\hline $1-4$ & $9(<1.0)$ & $* *$ & $8(1.3)$ & ** & $17(1.0)$ & ** \\
\hline $5-9$ & $1(<1.0)$ & $* *$ & $2(<1.0)$ & $* *$ & $3(<1.0)$ & $* *$ \\
\hline $10-14$ & $3(<1.0)$ & $* *$ & $5(<1.0)$ & $* *$ & $8(<1.0)$ & $* *$ \\
\hline $15-19$ & $29(2.7)$ & 0.9 & $12(1.9)$ & $* *$ & $41(2.4)$ & 0.6 \\
\hline $20-24$ & $89(8.3)$ & 2.5 & $40(6.4)$ & 1.2 & $129(7.6)$ & 1.9 \\
\hline $25-29$ & $102(9.5)$ & 3.1 & $54(8.6)$ & 1.7 & $156(9.2)$ & 2.4 \\
\hline $30-34$ & $104(9.7)$ & 3.3 & $66(10.5)$ & 2.1 & $170(10.0)$ & 2.7 \\
\hline $35-44$ & $199(18.6)$ & 3.2 & $108(17.2)$ & 1.7 & $307(18.1)$ & 2.5 \\
\hline $45-54$ & $257(24.0)$ & 3.9 & $170(27.1)$ & 2.5 & $427(25.1)$ & 3.2 \\
\hline $55-64$ & $181(16.9)$ & 3.1 & $98(15.6)$ & 1.6 & $279(16.4)$ & 2.3 \\
\hline $65-74$ & $41(3.8)$ & 1.1 & $24(3.8)$ & 0.6 & $65(3.8)$ & 0.8 \\
\hline $75-84$ & $13(1.2)$ & ** & $17(2.7)$ & $* *$ & $30(1.8)$ & 0.8 \\
\hline$\geq 85$ & $15(1.4)$ & $* *$ & $12(1.9)$ & $* *$ & $27(1.6)$ & 1.5 \\
\hline Unknown & $0(0)$ & $* *$ & $<1.0$ & $* *$ & $1(<1.0)$ & $* *$ \\
\hline Total & $1,070(100)$ & 2.3 & $628(100)$ & 1.3 & $1,698(100)$ & 1.8 \\
\hline \multicolumn{7}{|l|}{ Race/Ethnicity } \\
\hline White, non-Hispanic & $806(75.3)$ & 2.5 & $521(83.0)$ & 1.6 & $1,327(78.2)$ & 2.0 \\
\hline Black, non-Hispanic & $164(15.3)$ & 2.3 & $67(10.7)$ & 0.9 & 231 (13.6) & 1.6 \\
\hline American Indian/Alaska Native & $15(1.4)$ & ** & $10(1.6)$ & ** & $25(1.5)$ & 2.2 \\
\hline Asian/Pacific Islander & $11(1.0)$ & $* *$ & $8(1.3)$ & $* *$ & $19(1.1)$ & $* *$ \\
\hline Hispanic ${ }^{\dagger \dagger}$ & $68(6.4)$ & 1.3 & $17(2.7)$ & $* *$ & $85(5.0)$ & 0.8 \\
\hline Other & $2(<1.0)$ & $* *$ & $1(<1.0)$ & $* *$ & $3(<1.0)$ & $* *$ \\
\hline Unknown & $4(<1.0)$ & $* *$ & $4(<1.0)$ & $* *$ & $8(<1.0)$ & $* *$ \\
\hline Total & $1,070(100)$ & 2.3 & $628(100)$ & 1.3 & $1,698(100)$ & 1.8 \\
\hline \multicolumn{7}{|l|}{ Marital status $\S^{\S}$} \\
\hline Married & $225(22.0)$ & ११ & $160(26.7)$ & กา & $385(23.8)$ & ११ \\
\hline Never married & $470(46.0)$ & ११ & $193(32.2)$ & กา & $663(40.9)$ & ๆา \\
\hline Widowed & $34(3.3)$ & ก१ & $46(7.7)$ & ११ & $80(4.9)$ & ११ \\
\hline Divorced & $235(23.0)$ & ११ & $169(28.2)$ & กา & 404 (24.9) & ११ \\
\hline Married but separated & $14(1.4)$ & ११ & $13(2.2)$ & กา & $27(1.7)$ & ११ \\
\hline Single, not otherwise specified & $16(1.6)$ & ११ & $9(1.5)$ & १ศ & $25(1.5)$ & १ก \\
\hline Unknown & $27(2.6)$ & ११ & $9(1.5)$ & ११ & $36(2.2)$ & ११ \\
\hline Total & $1,021(100)$ & กๆ & $599(100)$ & กา & $1,620(100)$ & ๆา \\
\hline
\end{tabular}

* Percentages might not sum to $100 \%$ due to rounding.

† Per 100,000 population.

$\S$ Death that results from the use of force or power against oneself or another person for which evidence indicating one manner of death is no more compelling than evidence indicating another.

" Alaska, Colorado, Georgia, Kentucky, Maryland, Massachusetts, North Carolina, New Jersey, New Mexico, Ohio, Oklahoma, Oregon, Rhode Island, South Carolina, Utah, Virginia, and Wisconsin.

** Rate is not reported when number of deaths is $<20$ or when age or race/ethnicity is other or unknown.

$t^{+\dagger}$ Includes persons of any race.

$\S \S$ Includes decedents aged $\geq 18$ years only.

१ศ Rate cannot be computed for marital status because denominator is unknown. 
TABLE 26. Number and percentage* of deaths of undetermined intent, ${ }^{\dagger}$ by decedent's sex, method used, and location in which injury occurred — National Violent Death Reporting System, 17 states, $\$ 2013$

\begin{tabular}{|c|c|c|c|}
\hline & Male & Female & Total \\
\hline Characteristic & No. (\%) & No. $(\%)$ & No. (\%) \\
\hline \multicolumn{4}{|l|}{ Method } \\
\hline Poisoning & $687(64.2)$ & 458 (72.9) & $1,145(67.4)$ \\
\hline Firearm & $65(6.1)$ & $13(2.1)$ & $78(4.6)$ \\
\hline Blunt instrument & $44(4.1)$ & $17(2.7)$ & $61(3.6)$ \\
\hline Drowning & $38(3.6)$ & $15(2.4)$ & $53(3.1)$ \\
\hline Fall & $23(2.1)$ & $16(2.5)$ & $39(2.3)$ \\
\hline Hanging/strangulation/suffocation & $23(2.1)$ & $13(2.1)$ & $36(2.1)$ \\
\hline Fire/burns & $15(1.4)$ & $16(2.5)$ & $31(1.8)$ \\
\hline Motor vehicle (e.g., car, bus, motorcycle, other transport vehicle) & $23(2.1)$ & $5(<1.0)$ & $28(1.6)$ \\
\hline Personal weapons (e.g., hands, feet, fists) & $6(<1.0)$ & $1(<1.0)$ & $7(<1.0)$ \\
\hline Sharp instrument & $5(<1.0)$ & $0(0)$ & $5(<1.0)$ \\
\hline Intentional neglect & $0(0)$ & $2(<1.0)$ & $2(<1.0)$ \\
\hline Other (single method) & $8(<1.0)$ & $6(1.0)$ & $14(<1.0)$ \\
\hline Unknown & $133(12.4)$ & $66(10.5)$ & 199 (11.7) \\
\hline Total & $1,070(100)$ & $628(100)$ & $1,698(100)$ \\
\hline \multicolumn{4}{|l|}{ Location } \\
\hline House or apartment & $758(70.8)$ & $497(79.1)$ & 1,255 (73.9) \\
\hline Street or highway & $46(4.3)$ & $20(3.2)$ & $66(3.9)$ \\
\hline Natural area & $34(3.2)$ & $14(2.2)$ & $48(2.8)$ \\
\hline Hotel/motel & $22(2.1)$ & $14(2.2)$ & $36(2.1)$ \\
\hline Motor vehicle & $27(2.5)$ & $5(<1.0)$ & $32(1.9)$ \\
\hline Supervised residential facility & $13(1.2)$ & $5(<1.0)$ & $18(1.1)$ \\
\hline Commercial/retail area & $9(<1.0)$ & $4(<1.0)$ & $13(<1.0)$ \\
\hline Park, playground, sports/athletic area & $7(<1.0)$ & $3(<1.0)$ & $10(<1.0)$ \\
\hline Hospital or medical facility & $3(<1.0)$ & $4(<1.0)$ & $7(<1.0)$ \\
\hline Jail/prison & $6(<1.0)$ & $1(<1.0)$ & $7(<1.0)$ \\
\hline Bar/nightclub & $5(<1.0)$ & $1(<1.0)$ & $6(<1.0)$ \\
\hline Railroad tracks & $5(<1.0)$ & $1(<1.0)$ & $6(<1.0)$ \\
\hline Parking lot/public garage/public transport & $5(<1.0)$ & $0(0)$ & $5(<1.0)$ \\
\hline Abandoned house/building/warehouse & $3(<1.0)$ & $1(<1.0)$ & $4(<1.0)$ \\
\hline Office building & $2(<1.0)$ & $0(0)$ & $2(<1.0)$ \\
\hline Industrial or construction area & $1(<1.0)$ & $0(0)$ & $1(<1.0)$ \\
\hline Farm & $0(0)$ & $0(0)$ & $0(0)$ \\
\hline Preschool/school/college/school bus & $0(0)$ & $0(0)$ & $0(0)$ \\
\hline Other & $13(1.2)$ & $5(<1.0)$ & $18(1.1)$ \\
\hline Unknown & $111(10.4)$ & $53(8.4)$ & $164(9.7)$ \\
\hline Total & $1,070(100)$ & $628(100)$ & $1,698(100)$ \\
\hline
\end{tabular}

* Percentages might not total $100 \%$ due to rounding.

t Death that results from the use of force or power against oneself or another person for which evidence indicating one manner of death is no more compelling than evidence indicating another.

$\S$ Alaska, Colorado, Georgia, Kentucky, Maryland, Massachusetts, North Carolina, New Jersey, New Mexico, Ohio, Oklahoma, Oregon, Rhode Island, South Carolina, Utah, Virginia, and Wisconsin. 
TABLE 27. Number* and percentage of deaths of undetermined intent ${ }^{\dagger}$ decedents tested for alcohol and drugs and whose results were positive, $\$$ by toxicology variable - National Violent Death Reporting System, 17 states, 2013

\begin{tabular}{lcrrr}
\hline & Tested & & Positive \\
\cline { 2 - 2 } Toxicology variable & No. (\%) & & No. (\%) \\
\hline BAC & $1,331(78.4)$ & & $449(33.7)$ \\
Alcohol $<0.08 \mathrm{~g} / \mathrm{dL}$ & & $151(33.6)$ \\
Alcohol $\geq 0.08 \mathrm{~g} / \mathrm{dL}$ & & & $285(63.5)$ \\
Alcohol positive, level unknown & & & $13(2.9)$ \\
Amphetamines & $671(39.5)$ & & $112(16.7)$ \\
Anticonvulsants & $572(33.7)$ & & $112(19.6)$ \\
Antidepressants & $816(48.1)$ & & $438(53.7)$ \\
Antipsychotics & $576(33.9)$ & & $104(18.1)$ \\
Barbiturates & $591(34.8)$ & & $12(2.0)$ \\
Benzodiazepines & $848(49.9)$ & & $411(48.5)$ \\
Carbon monoxide & $209(12.3)$ & & $40(19.1)$ \\
Cocaine & $829(48.8)$ & & $197(23.8)$ \\
Marijuana & $553(32.6)$ & & $95(17.2)$ \\
Muscle relaxants & $552(32.5)$ & & $88(15.9)$ \\
Opiates & $1,276(75.1)$ & & $921(72.2)$ \\
Other drugs/substances ${ }^{\dagger \dagger}$ & $704(41.5)$ & & $703(99.9)$ \\
\hline
\end{tabular}

Abbreviation: $\mathrm{BAC}=$ blood alcohol concentration

* No. decedents $=1,698$.

† Death that results from the use of force or power against oneself or another person for which evidence indicating one manner of death is no more compelling than evidence indicating another.

$\S$ Percentage is of decedents tested for toxicology variable.

" Alaska, Colorado, Georgia, Kentucky, Maryland, Massachusetts, North Carolina, New Jersey, New Mexico, Ohio, Oklahoma, Oregon, Rhode Island, South Carolina, Utah, Virginia, and Wisconsin.

** $B A C \geq 0.08 \mathrm{~g} / \mathrm{dL}$ is over the legal limit in all states and is used as the standard for intoxication.

${ }^{+\dagger}$ Other drugs/substances indicated if any results were positive; levels for these drugs/substances are not measured. 
TABLE 28. Number* and percentage ${ }^{\dagger}$ of deaths of undetermined intent, ${ }^{\S}$ by precipitating circumstance and decedent's sex — National Violent Death Reporting System, 17 states, " 2013

\begin{tabular}{|c|c|c|c|}
\hline & Male & Female & Total \\
\hline Precipitating circumstance & No. (\%) & No. (\%) & No. (\%) \\
\hline \multicolumn{4}{|l|}{ Mental health/Substance abuse } \\
\hline Other substance abuse problem (excludes alcohol) & $569(64.6)$ & $341(63.0)$ & $910(64.0)$ \\
\hline Current diagnosed mental health problem & $289(32.8)$ & $272(50.3)$ & $561(39.5)$ \\
\hline History of ever being treated for a mental health problem & $290(32.9)$ & 259 (47.9) & 549 (38.6) \\
\hline Current mental health treatment & $240(27.2)$ & $228(42.1)$ & 468 (32.9) \\
\hline Alcohol problem & $279(31.7)$ & $104(19.2)$ & $383(26.9)$ \\
\hline Current depressed mood & $107(12.1)$ & 95 (17.6) & $202(14.2)$ \\
\hline Other addiction (e.g., gambling, sex) & $7(0.8)$ & $0(0)$ & $7(0.5)$ \\
\hline \multicolumn{4}{|l|}{ Interpersonal } \\
\hline Intimate partner problem & $74(8.4)$ & $60(11.1)$ & $134(9.4)$ \\
\hline Family relationship problem & $40(4.5)$ & $24(4.4)$ & $64(4.5)$ \\
\hline Other death of family member or friend within past 5 years & $23(2.6)$ & $28(5.2)$ & $51(3.6)$ \\
\hline Other relationship problem (nonintimate) & $13(1.5)$ & $4(0.7)$ & $17(1.2)$ \\
\hline Victim of interpersonal violence within past month & $9(1.0)$ & $6(1.1)$ & $15(1.1)$ \\
\hline Suicide of family member or friend within past 5 years & $5(<1.0)$ & $3(<1.0)$ & $8(<1.0)$ \\
\hline Perpetrator of interpersonal violence within past month & $3(<1.0)$ & $1(<1.0)$ & $4(<1.0)$ \\
\hline \multicolumn{4}{|l|}{ Life stressor } \\
\hline Physical health problem & $161(18.3)$ & $138(25.5)$ & $299(21.0)$ \\
\hline Crisis within previous or upcoming 2 weeks & $155(17.6)$ & $121(22.4)$ & $276(19.4)$ \\
\hline Argument or conflict & $56(6.4)$ & $37(6.8)$ & $93(6.5)$ \\
\hline Recent criminal legal problem & $29(3.3)$ & $14(2.6)$ & $43(3.0)$ \\
\hline Financial problem & $21(2.4)$ & $14(2.6)$ & $35(2.5)$ \\
\hline Job problem & $23(2.6)$ & $11(2.0)$ & $34(2.4)$ \\
\hline Eviction or loss of home & $19(2.2)$ & $6(1.1)$ & $25(1.8)$ \\
\hline Noncriminal legal problem & $9(1.0)$ & $14(2.6)$ & $23(1.6)$ \\
\hline Physical fight (two people, not a brawl) & $16(1.8)$ & $3(<1.0)$ & $19(1.3)$ \\
\hline History of child abuse/neglect & $8(<1.0)$ & $5(<1.0)$ & $13(<1.0)$ \\
\hline Caretaker abuse/neglect led to death & $6(<1.0)$ & $6(1.1)$ & $12(<1.0)$ \\
\hline Traumatic anniversary & $3(<1.0)$ & $3(<1.0)$ & $6(<1.0)$ \\
\hline School problem & $2(<1.0)$ & $2(<1.0)$ & $4(<1.0)$ \\
\hline Exposure to disaster & $2(<1.0)$ & $2(<1.0)$ & $4(<1.0)$ \\
\hline \multicolumn{4}{|l|}{ Crime and criminal activity } \\
\hline Precipitated by another crime & $20(2.3)$ & $0(0)$ & $20(1.4)$ \\
\hline Crime in progress ${ }^{\dagger \dagger}$ & $5(25.0)$ & $0(0)$ & $5(25.0)$ \\
\hline Terrorist attack & $0(0)$ & $0(0)$ & $0(0)$ \\
\hline \multicolumn{4}{|l|}{ Suicide event } \\
\hline History of suicide attempt & 95 (10.8) & $87(16.1)$ & $182(12.8)$ \\
\hline History of suicidal thoughts or plan & $82(9.3)$ & 79 (14.6) & $161(11.3)$ \\
\hline Left a suicide note & $11(1.2)$ & $11(2.0)$ & $22(1.5)$ \\
\hline \multicolumn{4}{|l|}{ Suicide disclosure } \\
\hline Disclosed suicide intent & $39(4.4)$ & $39(7.2)$ & $78(5.5)$ \\
\hline \multicolumn{4}{|l|}{ Disclosed intent to whom** } \\
\hline Other family member & $14(35.9)$ & $14(35.9)$ & $28(35.9)$ \\
\hline Previous or current intimate partner & $5(12.8)$ & $10(25.6)$ & $15(19.2)$ \\
\hline Friend/colleague & $5(12.8)$ & 4 (10.3) & $9(11.5)$ \\
\hline Health care worker & $4(10.3)$ & $4(10.3)$ & $8(10.3)$ \\
\hline Neighbor & $2(5.1)$ & $1(2.6)$ & $3(3.8)$ \\
\hline Other person & $3(7.7)$ & $3(7.7)$ & $6(7.7)$ \\
\hline Unknown & $6(15.4)$ & $3(7.7)$ & $9(11.5)$ \\
\hline Total deaths with precipitating circumstances & $881(100)$ & $541(100)$ & $1,422(100)$ \\
\hline
\end{tabular}

* Includes deaths with one or more precipitating circumstances. Circumstances were unknown for 276 decedents (189 males, 87 females). Numbers do not equal the sums of the columns because a death could have had more than one precipitating circumstance.

† Denominator includes only those decedents with one or more precipitating circumstances. Sums of percentages in columns exceed $100 \%$ because a death could have had more than one precipitating circumstance.

$\S$ Death that results from the use of force or power against oneself or another person for which evidence indicating one manner of death is no more compelling than evidence indicating another.

If Alaska, Colorado, Georgia, Kentucky, Maryland, Massachusetts, North Carolina, New Jersey, New Mexico, Ohio, Oklahoma, Oregon, Rhode Island, South Carolina, Utah, Virginia, and Wisconsin.

t† Denominator includes only those decedents involved in an incident that was precipitated by another crime.

** Denominator is decedents who disclosed intent. 
TABLE 29. Number* and percentage ${ }^{\dagger}$ of deaths of undetermined intent ${ }^{\S}$ decedents with a current diagnosed mental health problem, by diagnosis - National Violent Death Reporting System, 17 states, ${ }^{\mathbb{f}} 2013$

\begin{tabular}{|c|c|c|c|}
\hline & Male & Female & Total \\
\hline Diagnosed mental health problem & No. (\%) & No. $(\%)$ & No. (\%) \\
\hline Depression/dysthymia & $161(55.7)$ & $175(64.3)$ & $336(59.9)$ \\
\hline Anxiety disorder & $64(22.1)$ & $68(25.0)$ & $132(23.5)$ \\
\hline Bipolar disorder & $59(20.4)$ & $59(21.7)$ & $118(21.0)$ \\
\hline Schizophrenia & $28(9.7)$ & $12(4.4)$ & $40(7.1)$ \\
\hline PTSD & $15(5.2)$ & $2(<1.0)$ & $17(3.0)$ \\
\hline ADD/ADHD & $6(2.1)$ & $5(1.8)$ & $11(2.0)$ \\
\hline Eating disorder & $1(<1.0)$ & $4(1.5)$ & $5(<1.0)$ \\
\hline OCD & $0(0)$ & $1(<1.0)$ & $1(<1.0)$ \\
\hline Other & $23(8.0)$ & $23(8.5)$ & $46(8.2)$ \\
\hline Unknown & $41(14.2)$ & $37(13.6)$ & $78(13.9)$ \\
\hline Total decedents with a diagnosed mental health problem & $289(100)$ & $272(100)$ & $561(100)$ \\
\hline
\end{tabular}

Abbreviations: $\mathrm{PTSD}=$ posttraumatic stress disorder; $\mathrm{ADD} / \mathrm{ADHD}=$ attention deficit disorder/attention deficit hyperactivity disorder; $\mathrm{OCD}=$ obsessive-compulsive disorder.

* Includes decedents with one or more current diagnosed mental health problems. Numbers do not equal the sums of the columns because a decedent could have had more than one diagnosis.

$\dagger$ Denominator includes only those decedents with one or more current diagnosed mental health problems. Sums of percentages in columns exceed $100 \%$ because a decedent could have had more than one diagnosis.

$\S$ Death that results from the use of force or power against oneself or another person for which evidence indicating one manner of death is no more compelling than evidence indicating another.

" Alaska, Colorado, Georgia, Kentucky, Maryland, Massachusetts, North Carolina, New Jersey, New Mexico, Ohio, Oklahoma, Oregon, Rhode Island, South Carolina, Utah, Virginia, and Wisconsin.

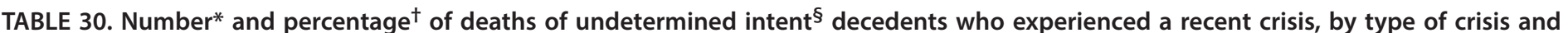
decedent's sex — National Violent Death Reporting System, 17 states, ${ }^{\mathfrak{9}} 2013$

\begin{tabular}{|c|c|c|c|}
\hline & Male & Female & Total \\
\hline Type of crisis & No. (\%) & No. (\%) & No. (\%) \\
\hline Physical health problem & $42(27.1)$ & $51(42.1)$ & 93 (33.7) \\
\hline Other substance abuse problem & $34(21.9)$ & $25(20.7)$ & $59(21.4)$ \\
\hline Intimate partner problem & $32(20.6)$ & $19(15.7)$ & $51(18.5)$ \\
\hline Family relationship problem & $13(8.4)$ & $8(6.6)$ & $21(7.6)$ \\
\hline Alcohol problem & $8(5.2)$ & $8(6.6)$ & $16(5.8)$ \\
\hline Criminal legal problem & $11(7.1)$ & $4(3.3)$ & $15(5.4)$ \\
\hline Eviction or loss of home & $12(7.7)$ & $3(2.5)$ & $15(5.4)$ \\
\hline Other death of friend or family & $9(5.8)$ & $6(5.0)$ & $15(5.4)$ \\
\hline Current diagnosed mental health problem & $4(2.6)$ & $3(2.5)$ & $7(2.5)$ \\
\hline Job problem & $4(2.6)$ & $3(2.5)$ & $7(2.5)$ \\
\hline Other relationship problem & $3(1.9)$ & $2(1.7)$ & $5(1.8)$ \\
\hline Financial problem & $1(<1.0)$ & $3(2.5)$ & $4(1.4)$ \\
\hline School problem & $2(1.3)$ & $1(<1.0)$ & $3(1.1)$ \\
\hline Noncriminal legal problem & $0(0)$ & $2(1.7)$ & $2(<1.0)$ \\
\hline Suicide of friend or family member & $2(1.3)$ & $0(0)$ & $2(<1.0)$ \\
\hline Other addiction (e.g., gambling, sex) & $0(0)$ & $0(0)$ & $0(0)$ \\
\hline Disaster exposure & $0(0)$ & $0(0)$ & $0(0)$ \\
\hline Other crisis & $19(12.3)$ & $20(16.5)$ & $39(14.1)$ \\
\hline Total decedents who experienced a recent crisis & $155(100)$ & $121(100)$ & $276(100)$ \\
\hline
\end{tabular}

* Includes decedents who experienced one or more crises within the previous or upcoming 2 weeks. Numbers do not equal the sums of the columns because a decedent could have experienced more than one crisis.

$\dagger$ Denominator includes only those decedents who experienced one or more crises within the previous or upcoming 2 weeks. Sums of percentages in columns exceed $100 \%$ because a decedent could have experienced more than one crisis.

$\S$ Death that results from the use of force or power against oneself or another person for which evidence indicating one manner of death is no more compelling than evidence indicating another.

I Alaska, Colorado, Georgia, Kentucky, Maryland, Massachusetts, North Carolina, New Jersey, New Mexico, Ohio, Oklahoma, Oregon, Rhode Island, South Carolina, Utah, Virginia, and Wisconsin. 
TABLE 31. Number* and percentage ${ }^{\dagger}$ of unintentional firearm deaths, by decedent's sex, race/ethnicity, age group, month in which the death occurred, location where injury occurred, and type of firearm — National Violent Death Reporting System, 17 states, § 2013

\begin{tabular}{|c|c|}
\hline Characteristic & No. (\%) \\
\hline \multicolumn{2}{|l|}{ Sex } \\
\hline Male & $107(85.6)$ \\
\hline Female & $18(14.4)$ \\
\hline Total & $125(100)$ \\
\hline \multicolumn{2}{|l|}{ Race/Ethnicity } \\
\hline White, non-Hispanic & $98(78.4)$ \\
\hline Black, non-Hispanic & $16(12.8)$ \\
\hline American Indian/Alaska Native & $3(2.4)$ \\
\hline Asian/Pacific Islander & $1(<1.0)$ \\
\hline Hispanic & $4(3.2)$ \\
\hline Other & $1(<1.0)$ \\
\hline Unknown & $2(1.6)$ \\
\hline Total & $125(100)$ \\
\hline \multicolumn{2}{|l|}{ Age group (yrs) } \\
\hline$<1$ & $0(0)$ \\
\hline $1-4$ & $6(4.8)$ \\
\hline $5-9$ & $6(4.8)$ \\
\hline $10-14$ & $4(3.2)$ \\
\hline $15-19$ & $21(16.8)$ \\
\hline $20-24$ & $15(12.0)$ \\
\hline $25-29$ & $15(12.0)$ \\
\hline $30-34$ & $5(4.0)$ \\
\hline $35-44$ & $7(5.6)$ \\
\hline $45-54$ & $16(12.8)$ \\
\hline $55-64$ & $18(14.4)$ \\
\hline $65-74$ & $5(4.0)$ \\
\hline $75-84$ & $6(4.8)$ \\
\hline$\geq 85$ & $1(<1.0)$ \\
\hline Total & $125(100)$ \\
\hline \multicolumn{2}{|l|}{ Month } \\
\hline January & $9(7.2)$ \\
\hline February & $10(8.0)$ \\
\hline March & $13(10.4)$ \\
\hline April & $13(10.4)$ \\
\hline May & $8(6.4)$ \\
\hline June & $6(4.8)$ \\
\hline July & $11(8.8)$ \\
\hline August & $9(7.2)$ \\
\hline September & $7(5.6)$ \\
\hline October & $13(10.4)$ \\
\hline November & $13(10.4)$ \\
\hline December & $13(10.4)$ \\
\hline Total & $125(100)$ \\
\hline
\end{tabular}

TABLE 31. (Continued) Number* and percentage ${ }^{\dagger}$ of unintentional firearm deaths, by decedent's sex, race/ethnicity, age group, month in which the death occurred, location where injury occurred, and type of firearm — National Violent Death Reporting System, 17 states, $\$ 2013$

\begin{tabular}{lr}
\hline Characteristic & No. $(\%)$ \\
\hline Location & \\
House or apartment & $87(69.6)$ \\
Natural area & $13(10.4)$ \\
Motor vehicle & $3(2.4)$ \\
Hotel/motel & $2(1.6)$ \\
Parking lot/public garage/public transport & $1(<1.0)$ \\
Railroad tracks & $1(<1.0)$ \\
Street/highway & $1(<1.0)$ \\
Other** & $4(3.2)$ \\
Unknown & $13(10.4)$ \\
Total & $125(100)$ \\
Type of firearm & \\
Handgun & $58(46.4)$ \\
Shotgun & $20(16.0)$ \\
Rifle & $15(12.0)$ \\
Other firearm & $0(0)$ \\
Unknown & $32(25.6)$ \\
Total & $125(100)$ \\
\hline
\end{tabular}

* No. deaths $=125$.

${ }^{+}$Percentages might not total $100 \%$ due to rounding.

$\S$ Alaska, Colorado, Georgia, Kentucky, Maryland, Massachusetts, North Carolina, New Jersey, New Mexico, Ohio, Oklahoma, Oregon, Rhode Island, South Carolina, Utah, Virginia, and Wisconsin.

I" Includes persons of any race.

** Includes military training exercise, private land campsites, and private hunting land attached to homes. 
TABLE 32. Number* and percentage ${ }^{\dagger}$ of unintentional firearm deaths, by context and circumstance of injury - National Violent Death Reporting System, 17 states ${ }^{\S}, 2013$

\begin{tabular}{lr}
\hline Characteristic & No. (\%) \\
\hline Context of injury & \\
Playing with gun & $28(28.9)$ \\
Hunting & $13(13.4)$ \\
Cleaning gun & $11(11.3)$ \\
Showing gun to others & $8(8.2)$ \\
Loading/unloading gun & $6(6.2)$ \\
Target shooting & $2(2.1)$ \\
Celebratory firing & $0(0)$ \\
Other context of injury & $32(33.0)$ \\
Circumstance of injury & \\
Unintentionally pulled trigger & $20(20.6)$ \\
Thought gun was unloaded & $14(14.4)$ \\
Thought gun was unloaded, magazine disengaged & $8(8.2)$ \\
Gun was dropped & $4(4.1)$ \\
Gun fired while handling safety lock & $3(3.1)$ \\
Gun was mistaken for a toy & $3(3.1)$ \\
Gun fired due to defect or malfunction & $2(2.1)$ \\
Thought gun safety was engaged & $1(1.0)$ \\
Bullet ricocheted & $1(1.0)$ \\
Gun fired while holstering & $0(0)$ \\
Other mechanism of injury & $23(23.7)$ \\
\hline * Includes 97 deaths with one or more circumstances known. Circumstances & \\
were unknown for 28 deaths. & \\
† Percentages might exceed 100\% because one or more circumstances could \\
have been known per death; therefore, number and percentage are reported \\
when the number of deaths is <5 because no particular circumstance identifies \\
§ single death. & \\
§ Alaska, Colorado, Georgia, Kentucky, Maryland, Massachusetts, North Carolina, \\
New Jersey, New Mexico, Ohio, Oklahoma, Oregon, Rhode Island, South \\
Carolina, Utah, Virginia, and Wisconsin. & \\
&
\end{tabular}





The Morbidity and Mortality Weekly Report (MMWR) Series is prepared by the Centers for Disease Control and Prevention (CDC) and is available free of charge in electronic format. To receive an electronic copy each week, visit MMWR's free subscription page at http://www.cdc.gov/mmwr/mmwrsubscribe.html. Paper copy subscriptions are available through the Superintendent of Documents, U.S. Government Printing Office, Washington, DC 20402; telephone 202-512-1800.

Readers who have difficulty accessing this PDF file may access the HTML file at http://www.cdc.gov/mmwr/volumes/65/ss/ss6510a1.htm?s_cid=ss6510a1_w. Address all inquiries about the $M M W R$ Series, including material to be considered for publication, to Executive Editor, MMWR Series, Mailstop E-90, CDC, 1600 Clifton Rd., N.E., Atlanta, GA 30329-4027 or to mmwrq@cdc.gov.

All material in the MMWR Series is in the public domain and may be used and reprinted without permission; citation as to source, however, is appreciated. Use of trade names and commercial sources is for identification only and does not imply endorsement by the U.S. Department of Health and Human Services.

References to non-CDC sites on the Internet are provided as a service to $M M W R$ readers and do not constitute or imply endorsement of these organizations or their programs by CDC or the U.S. Department of Health and Human Services. CDC is not responsible for the content of these sites. URL addresses listed in $M M W R$ were current as of the date of publication.

ISSN: 1546-0738 (Print) 